\title{
Microstructural analysis of inherent and induced anisotropy in clay
}

\author{
P. Y. Hicher, ${ }^{1}$ H. Wahyudi ${ }^{2}$ and D. Tessier ${ }^{3}$ \\ ${ }^{1}$ Laboratoire de Génie Civil de Nantes - Saint-Nazaire, Ecole Centrale de Nantes, B.P. 92101, 44321 Nantes Cédex 3, \\ France \\ ${ }^{2}$ Teknik Kelautan, University of Surabaya, Indonesia \\ ${ }^{3}$ INRA, Laboratoire de Science du Sol, Route de Saint Cyr, Versailles, France
}

The aim of this study was to relate the mechanical behaviour of saturated clays to their structural characteristics. Two clays were studied: a kaolinite and a bentonite. The evolution of the shape, the size, the concentration and the orientation of the elements which constitute the clay structure was examined by means of scanning and transmission electron microscopes. Particular care was taken to avoid as far as possible disturbing the micro-structure during observation. The results showed the existence of particle breakage and the creation of structural anisotropy during loading. We can conclude from this work that the mechanical behaviour to clayed materials is largely dependent on the changes which occur at the scale of the particles.

KEY WORDS: clay structure, anisotropy; triaxial tests; oedometer tests; scanning electron microscopy; transmission electron microscopy

\section{INTRODUCTION}

Soils in general, and particularly saturated and non-saturated clays, are usually characterized by their 'macroscopic' mechanical properties, that is, at the scale of the sample or at larger scales for in situ testing. Their macroscopic behaviour can be represented by their stress-strain relationships [1-4] and analysis of their properties at the scale of the crystal unit is usually done in the framework of physico-chemical or crystallographic studies which seek to determine a type of crystal, the ion exchange capacity, the number of exchangeable cations, the inter-crystal distance in relation to the type of water, etc. [5-12].

Since these two types of characterizing affect two completely different scales of investigation, it is highly difficult to relate the macroscopic properties to the different heterogeneities of the studied systems, especially those which correspond to larger scales than the clay crystals themselves, i.e. particles and associations of particles, aggregates, fissures, etc. The evolution of 
the microstructure during one-dimensional consolidation has been studied by Pusch [13], Martin and Ladd [14], Delage and Lefebvre [15] and others. Several authors have also reported observations of microstructure and pore-size distribution in relation to the permeability of clayey materials [15-17].

The aim of this study is to provide some evidence of the connections between the evolution of the clay structures at different scales of observation and the mechanical behaviour of clayey materials subjected to different stress and strain loadings. We are particularly interested in connecting structural and mechanical anisotropy. For this purpose, different methods of investigation have been used to allow us to describe the clay structure at scales between $1 \mathrm{~mm}$ and $10 \AA$ along the one-dimensional and triaxial loadings.

In the following, terms referring to clay structure are defined as follows:

1. Clay layer: the elementary unit of structure comprising stacked units of tetrahedral and octahedral sheets forming the given clay mineral unit cell.

2. Crystal that consist of several layers having exact parallel orientation of $a-b$ planes (Méring and Oberlin, 1971).

3. Clay particle formed by nearly parallel face-to-face grouping of crystals or stacking of elementary clay layer units into compound tactoid of quasi-crystal (Quirk and Aylmore, 1971).

4. Aggregates made up of particles that are not easily disaggregated and that contain voids or internal discontinuities between them.

\section{TESTED MATERIALS AND METHODS}

We studied two different clays: a kaolinite and a bentonite, whose structural organizations are very different. Table I summarizes their physical properties. A slurry was first prepared at a water content equal to two times the liquid limit. Figures 1 and 2 present observations from scanning electron microscope (SEM) by the use of the low-temperature technique (CRYOSCAN) $[18,19]$.

Table I. Physical properties of studied clays

\begin{tabular}{lcc}
\hline Properties & Kaolinite & Bentonite \\
\hline Mineralogy & $\begin{array}{c}\text { Kaolinite } \\
\text { few illite, quartz }\end{array}$ & $\begin{array}{c}\text { Smectite Mg } \\
\text { few feldspar, illite, } \\
\text { quartz }\end{array}$ \\
Specific surface of the clay powder $\left(\mathrm{m}^{2} / \mathrm{g}\right)$ & 10.80 & 288.38 \\
$\%<80 \mu \mathrm{m}$ & 96 & 79 \\
$\%<2 \mu \mathrm{m}$ & 47 & 67 \\
Liquid limit $W_{\mathrm{L}}(\%)$ & 40 & 100 \\
Plastic limit $W_{\mathrm{P}}(\%)$ & 20 & 46 \\
Activity & 0.42 & 0.80 \\
Volumetric weight of the solid $\gamma_{\mathrm{S}}\left(\mathrm{t} / \mathrm{m}^{3}\right)$ & 2.65 & 2.70 \\
Swelling index $C_{\mathrm{S}}$ & 0.049 & 0.128
\end{tabular}




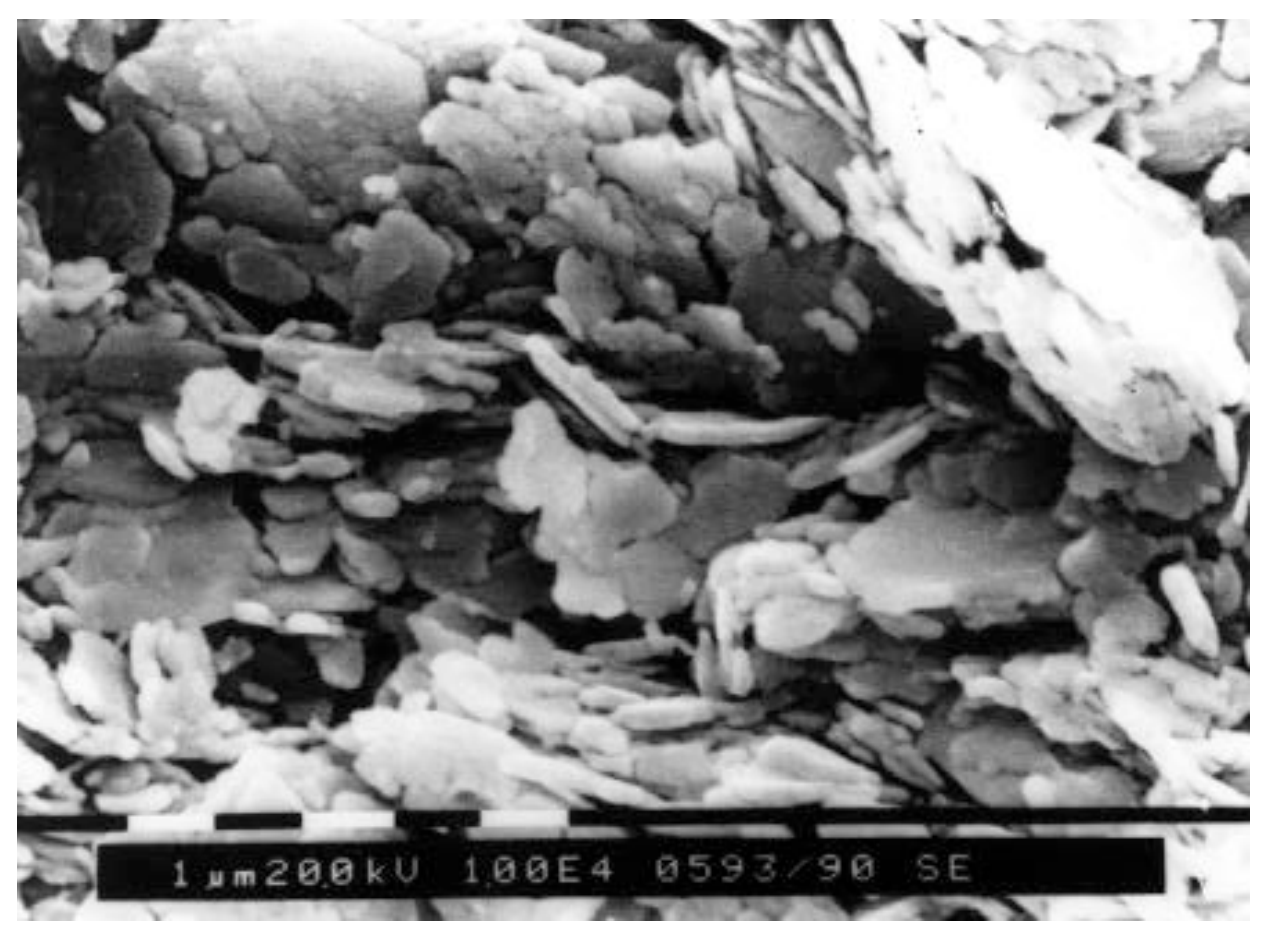

Figure 1. Observation of kaolinite slurry by SEM.

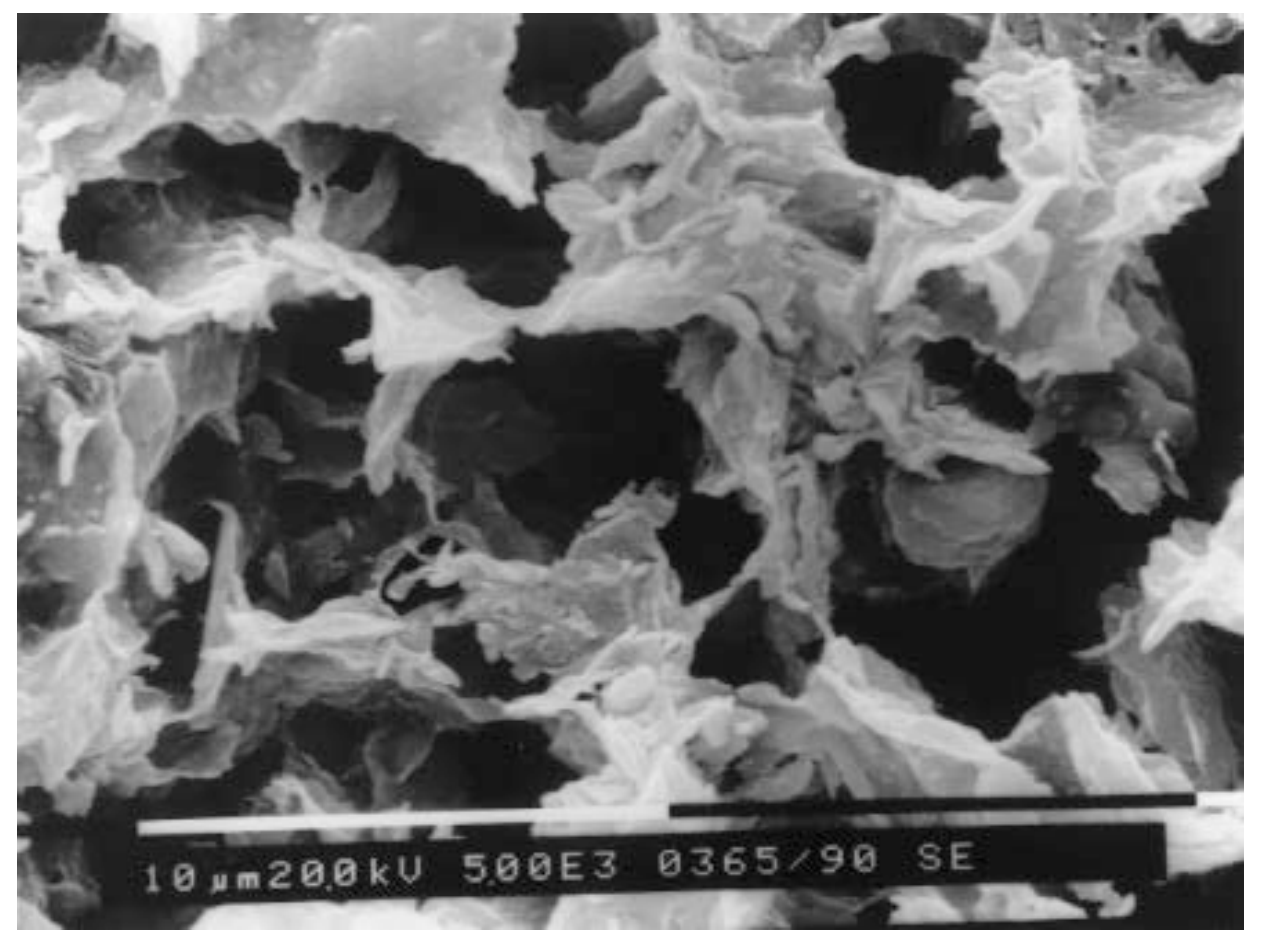

Figure 2. Observation of bentonite slurry by SEM.

The sequence of the specimen preparation for all SEM observations is the following:

1. Freezing into nitrogen liquid at $-196^{\circ} \mathrm{C}$.

2. Fracture specimen in cryochamber.

3. Sublimation in SEM at $-80^{\circ} \mathrm{C}$ for $10 \mathrm{~min}$.

4. Sputter coat in chamber for $3 \mathrm{~min}$.

5. Examination and photography at $-160^{\circ} \mathrm{C}$. 
The microstructures of the two clays appear very different, in agreement with numerous studies on clay structures $[8,10]$. For the bentonite slurry, we can observe large voids limited by solid particles of large lateral extension and of strongly variable shapes. These aggregates represent roughly face-to-face associations of crystals made up of numerous layers with variable layer distances. The microstructure of the kaolinite slurry appears more compact, with voids of smaller sizes and aggregates of variable sizes, particularly in thickness. The crystals are roughly associated face to face, giving clay particles. Compared to the bentonite aggregates, they are more regularly shaped (platelets), flat and smaller (maximum length in the order of $10 \mu \mathrm{m}$ ). The layer distance $(7 \AA)$ corresponds to the kaolinite crystal.

At the level of individual clay layers, a transmission electron microscope (TEM) can be used. The procedure followed in this study has already been presented by Tessier [20]. Water within the samples (section only $50 \mathrm{~nm}$ thick) was successively replaced by methanol, propylene oxide and finally by Spurr's epoxy resin. The exchange occurred in a liquid medium so that any variation in the bulk volume of the sample could be prevented. After hardening and ultramicrotomy, the lattice images that correspond to each layer and interlayer distances could be observed under TEM. It was therefore possible to observe the organization of the crystals which constitute a clay particle. Each crystal is made up of a certain number of layers. The kaolinite particles were formed by thick and rigid aggregates of layers, while the bentonite particles appeared to be made of larger and more supple layers. These layers could be easily observed in the case of the bentonite (Figure 3).

The microstructure study was completed by the use of mercury intrusion porosimetry (MIP) to provide the pore size distribution inside the specimen at different loading points. This technique has been reported and discussed by different authors. Among them, Gillott [21], Delage and Lefebvre [15], Griffiths and Joshi [17] demonstrated that it is highly suitable for the study of clay microstructure, provided that the sample is dehydrated using a freeze-drying method. In these conditions the authors showed that the data from SEM and MIP were in good agreement; intra-aggregates spaces measured by SEM were of the same order of magnitude as those given by MIP. In conducting tests with the SEM or the TEM, we were obliged to extract small fragments

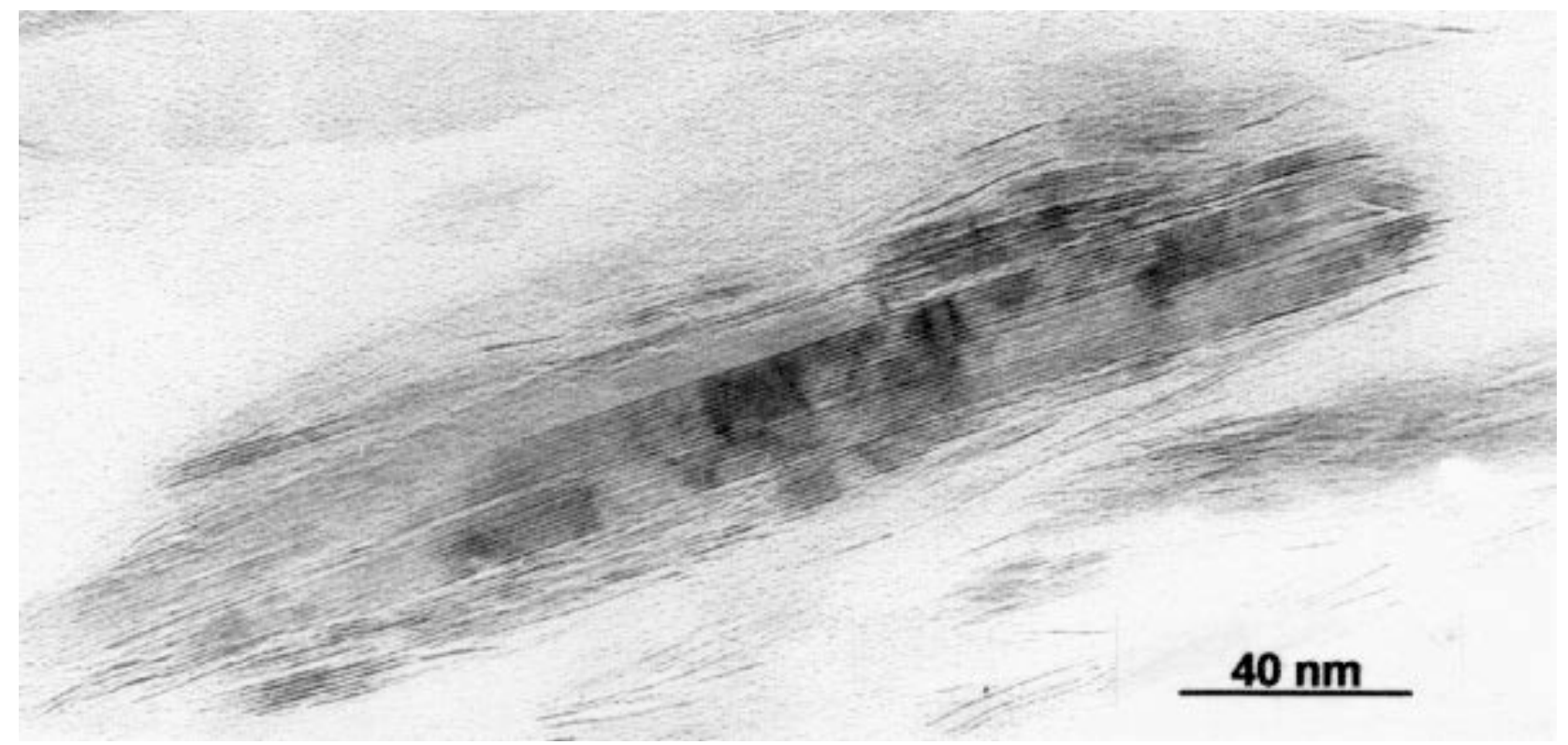

Figure 3. Observation of bentonite at particle scale by TEM. 
from the samples whereupon it was always possible that the structures could be slightly disturbed. Furthermore, these fragments had to be treated either for the SEM Cryoscan technique or by exchanging the pore water with resin in the case of TEM. While interpreting these results on their own could prove to be a delicate matter, the use of complementary methods, such as MIP, could do much to support and to enhance these microscopic observations.

\section{TESTING PROGRAMME}

We performed two types of mechanical testing: a consolidated drained triaxial test and a onedimensional consolidation test.

One-dimensional and isotropic consolidation test results produced very different compressibility coefficients $\left(C_{\mathrm{C}}\right)$ for the two clays (Figures 4 and 5). For the kaolinite, $C_{\mathrm{C}}$ was constant and equal to 0.23 in the stress range $100-6000 \mathrm{kPa}$. For the bentonite $C_{\mathrm{C}}$ decreased with the stress increase from 1.5 for stress between 100 and $1000 \mathrm{kPa}$ down to 0.23 for the maximum applied stress $(6000 \mathrm{kPa})$, i.e. close to the value obtained for the kaolinite. In both the cases the isotropic and one-dimensional consolidation curves are parallel in the plane void ratio-mean effective stress. For a given mean effective stress the void ratio is higher in the case of isotropic consolidation. All these results will be discussed below in relation to the observations of the microstructure.

Drained triaxial tests were performed on normally consolidated and overconsolidated samples $(\mathrm{OCR}=10)$. Some results are presented in Figures 6-9. Normally consolidated clays were always contractant while overconsolidated samples were contractant at the beginning of loading and then dilatant up to failure. Under failure conditions, microstructural analyses of strain localization have been performed and presented previously [22]. In a narrow zone along the

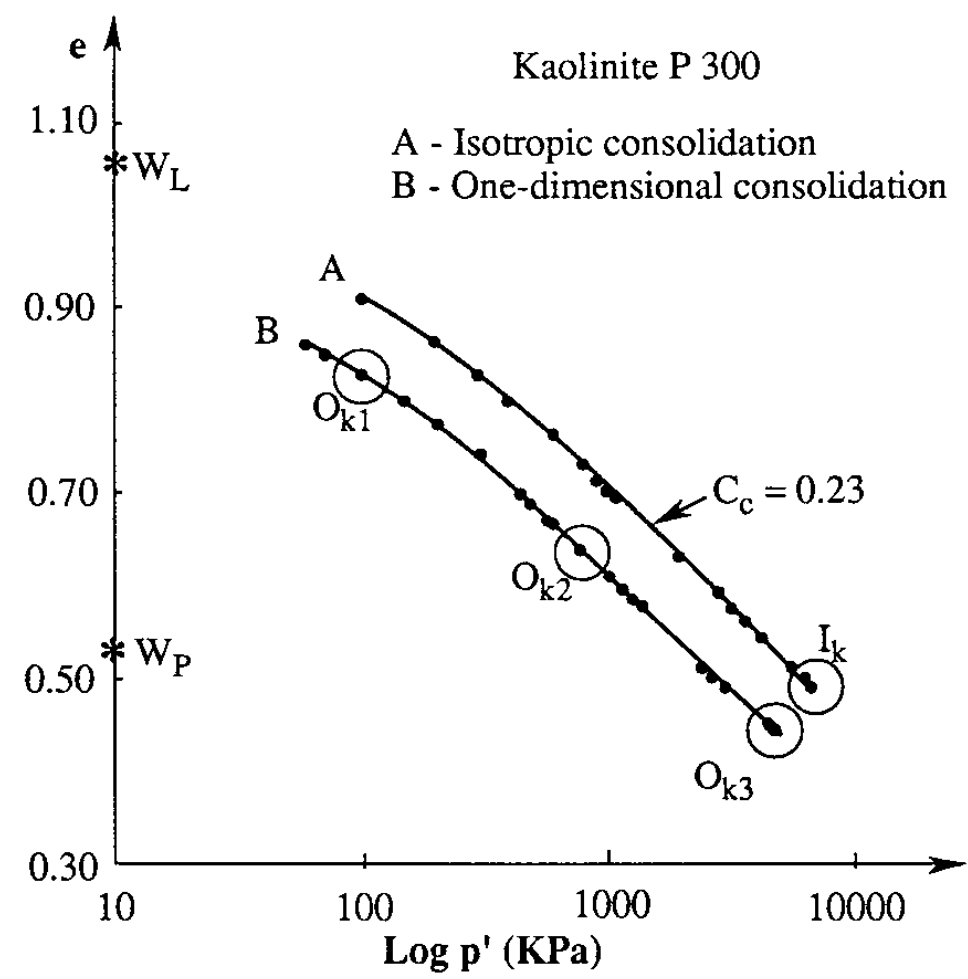

Figure 4. Isotropic and one-dimensional consolidation of kaolinite specimen. 


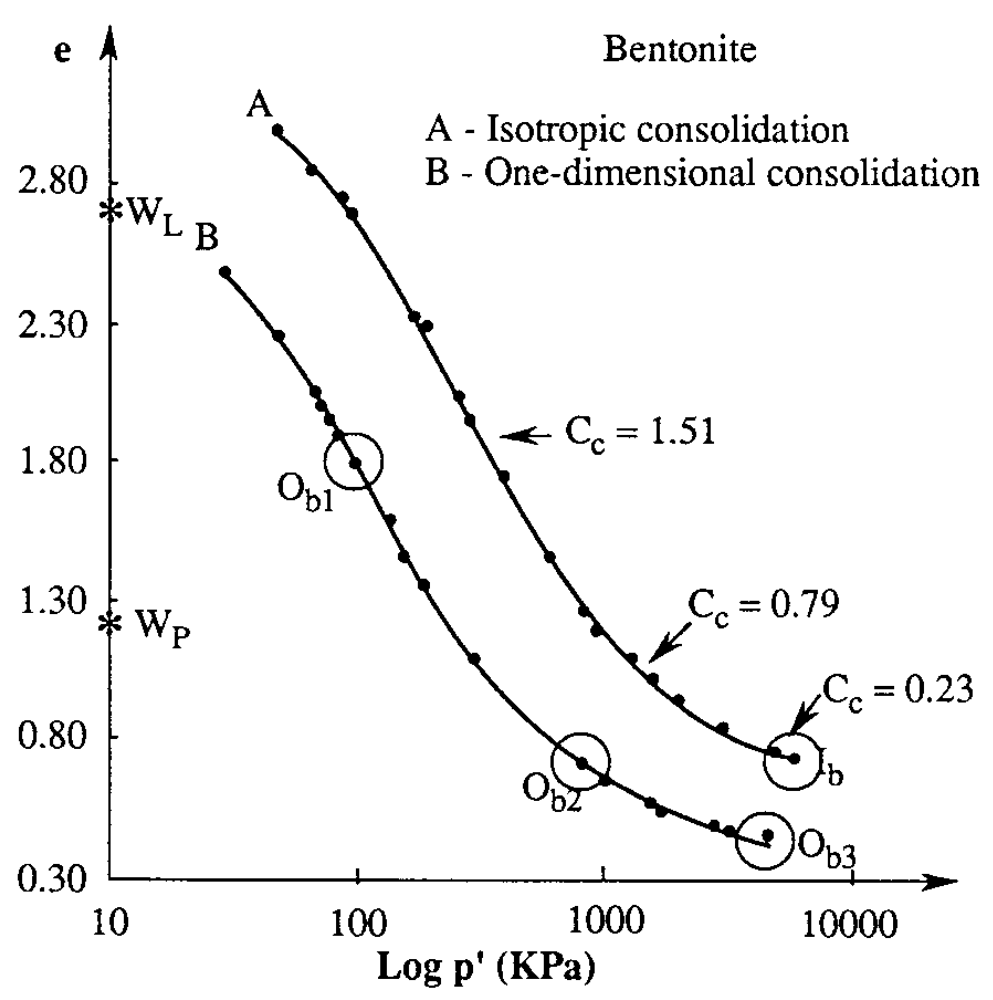

Figure 5. Isotropic and one-dimensional consolidation of bentonite specimen.

failure surface, a strong reorientation and a breaking of the particles take place, creating maximum anisotropy. Large displacements and large rotations of particles are necessary to obtain this result.

The tests were stopped at different values of axial strain. The samples were then cut into small parts and the structure was analysed by different techniques. In each case, we examined two orientations of the cutting: in horizontal and in vertical planes. This procedure allowed us to follow the evolution of the clay structure during mechanical loading.

\section{RESULTS OBTAINED ON KAOLINITE}

The states which were analyzed by the SEM technique correspond to point $\mathrm{O}_{\mathrm{K} 1}, \mathrm{O}_{\mathrm{K} 2}, \mathrm{O}_{\mathrm{K} 3}$ of the one-dimensional consolidation test, to point $I_{K}$ of the isotropic consolidation test (Figure 4), to point $\mathrm{A}, \mathrm{B}, \mathrm{C}$ of the normally consolidated triaxial test (Figure 6), and to point D, E, F of the over consolidated triaxial test (Figure 7).

\section{Isotropic and one-dimensional consolidation tests}

The points of observations $A, \mathrm{I}_{K}(\mathrm{OCR}=1)$ and $\mathrm{D}(\mathrm{OCR}=10)$ correspond to different isotropic consolidation stresses. In Figures 10 and 11 we can see that the general orientation of clay particles is isotropic: there is no preferential organization in either the horizontal or vertical planes. The particles are plate shaped and form aggregates with a maximum diameter of about $10 \mu \mathrm{m}$. The mean size of an individual particle is $1.1 \times 0.8 \mu \mathrm{m}$. Generally, the particles are associated edge-face although some face-face associations can also be observed. 

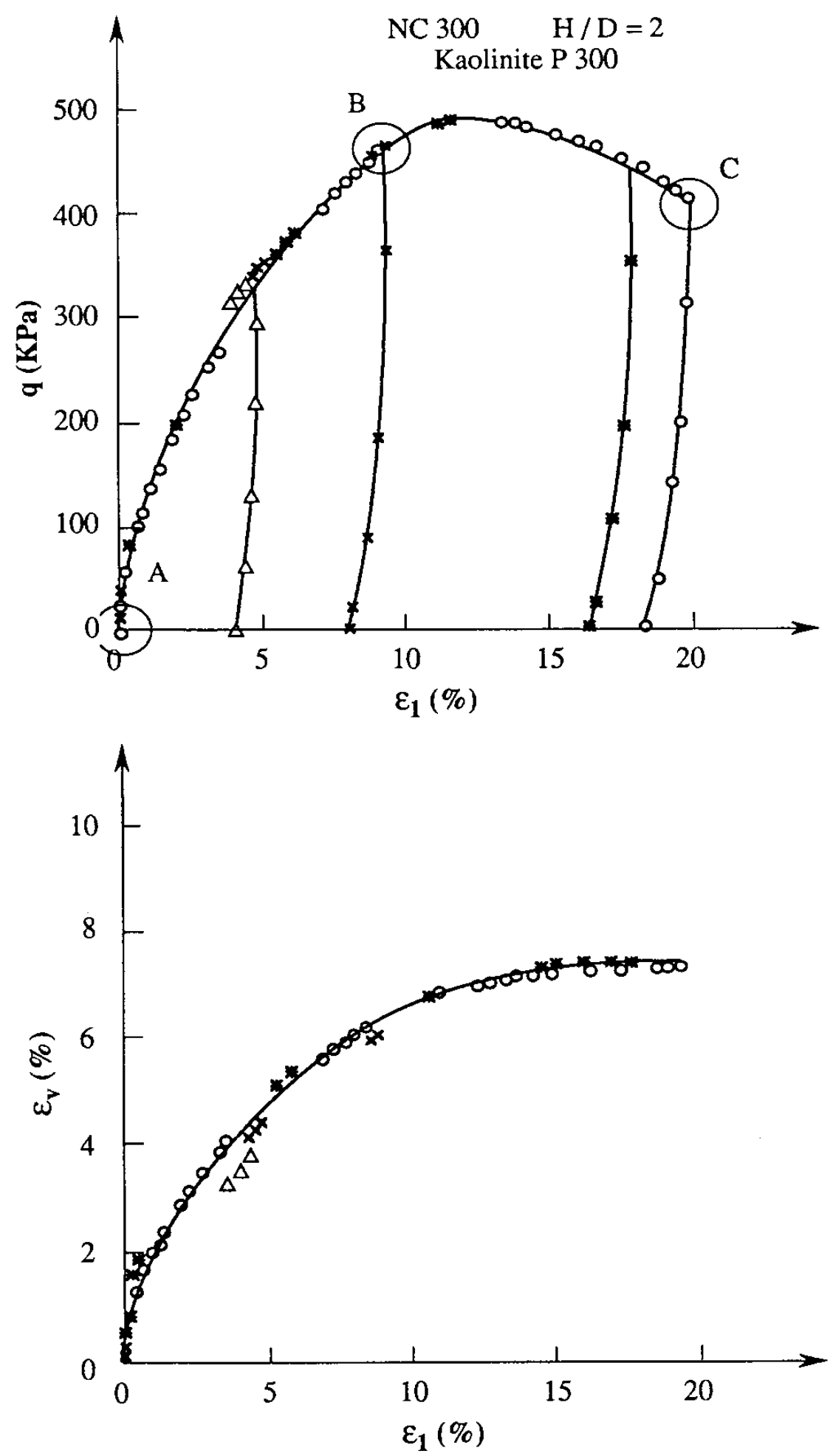

Figure 6. Drained triaxial test on normally consolidated kaolinite.

Point $\mathrm{A}(0.3 \mathrm{MPa})$ and $\mathrm{D}(0.1 \mathrm{MPa})$ correspond to almost identical void ratios $(e=0.75)$. In the corresponding figures, we can observe an identical density of particles, but the mean particles size is lower in the case of the overconsolidated sample, subjected to a higher maximum stress (1 MPa) which caused some aggregates to break. This phenomenon is found to be even more pronounced for the state represented by $\mathrm{I}_{\mathrm{K}}$ with the consolidation pressure of $6 \mathrm{MPa}$. Here we can also see a strong densification of the sample $(e=0.5)$. 

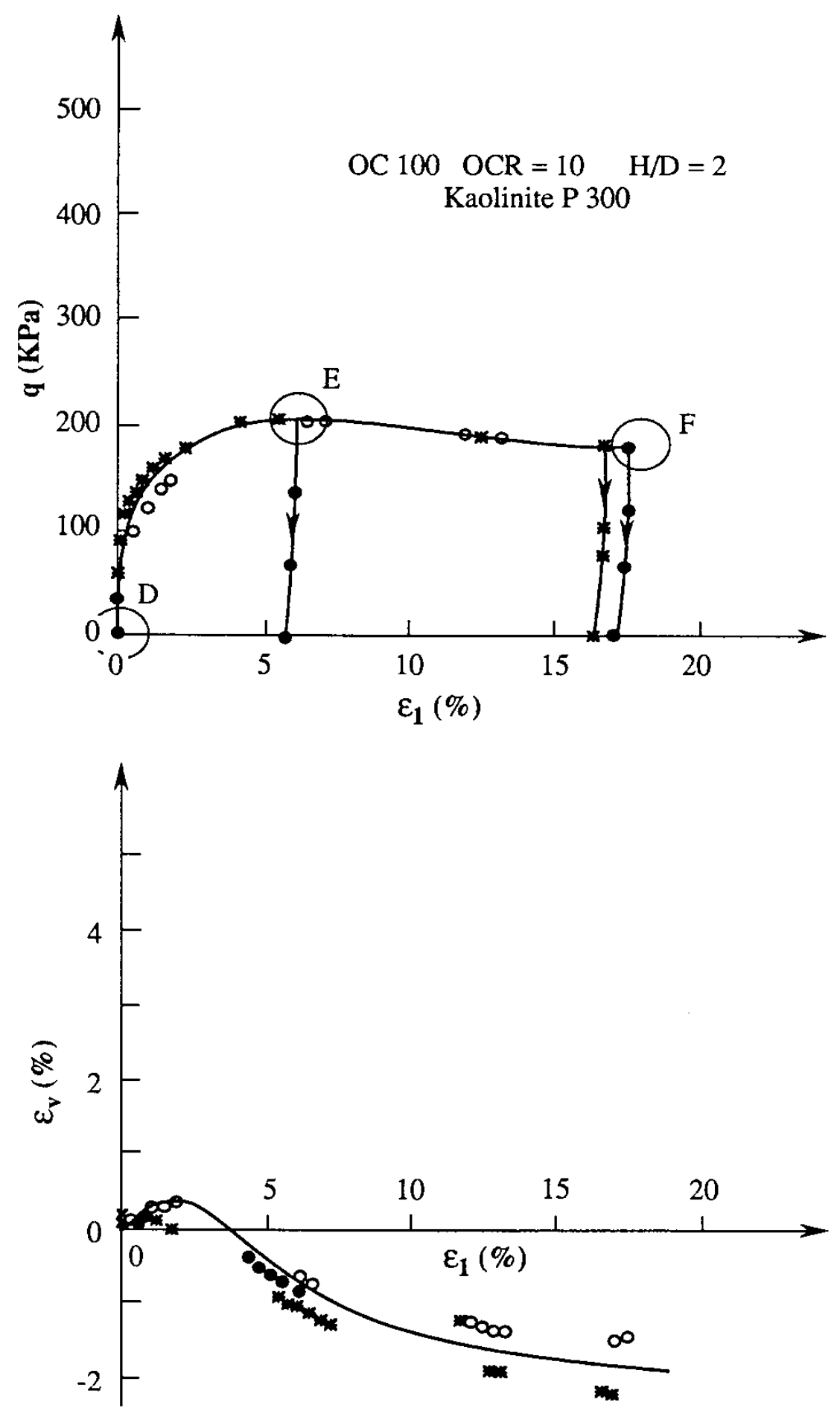

Figure 7. Drained triaxial test on over consolidated kaolinite.

The examination of points $\mathrm{O}_{\mathrm{K} 3}$ (Figures 4 and 12) correspond to one-dimensional consolidations of $6.3 \mathrm{MPa}$. At this stress the organization is strongly anisotropic with a predominance of face-face associations. In this case the dimensions of the pores can become smaller rather than in the case of an isotropic organisation where the association is mainly side-face. As a consequence, for the same mean effective stress, the void ratio is smaller in the case of one-dimensional consolidation than in the case of isotropic consolidation (Figure 4). 

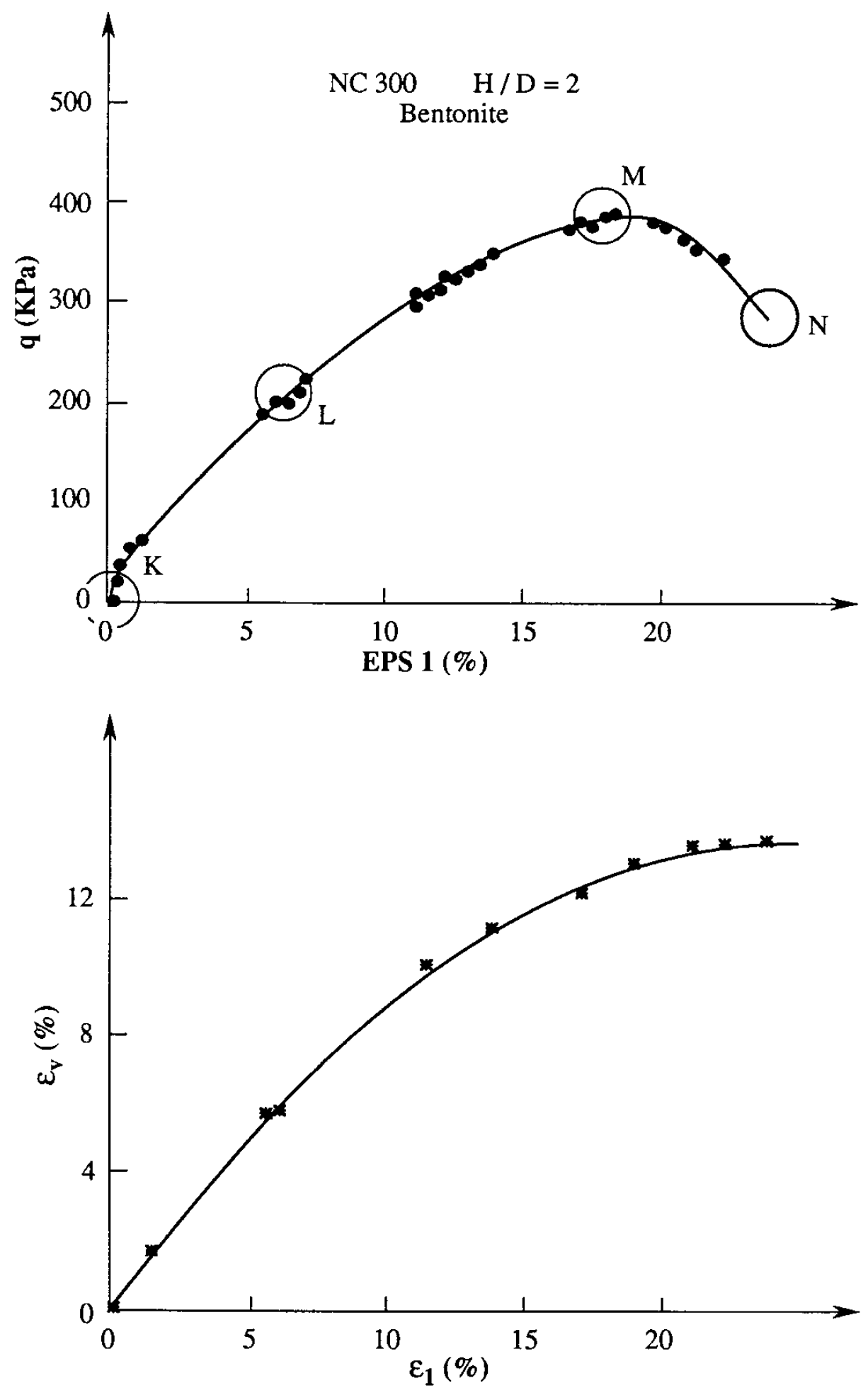

Figure 8. Drained triaxial test on normally consolidated bentonite.

\section{Drained triaxial tests}

The observation point B and C (Figure 6) correspond to drained triaxial compression of normally consolidated samples sheared up to axial stress of 9 and 19.5 per cent, respectively. We can observe in Figure 13 the state of the clay structure at point C. On a horizontal plane the particle orientation is isotropic, while on a vertical plane, we can observe at point $\mathrm{C}$ a reorientation of the particles forming an anisotropic structure. We can also observe a decrease of the numbers of large 

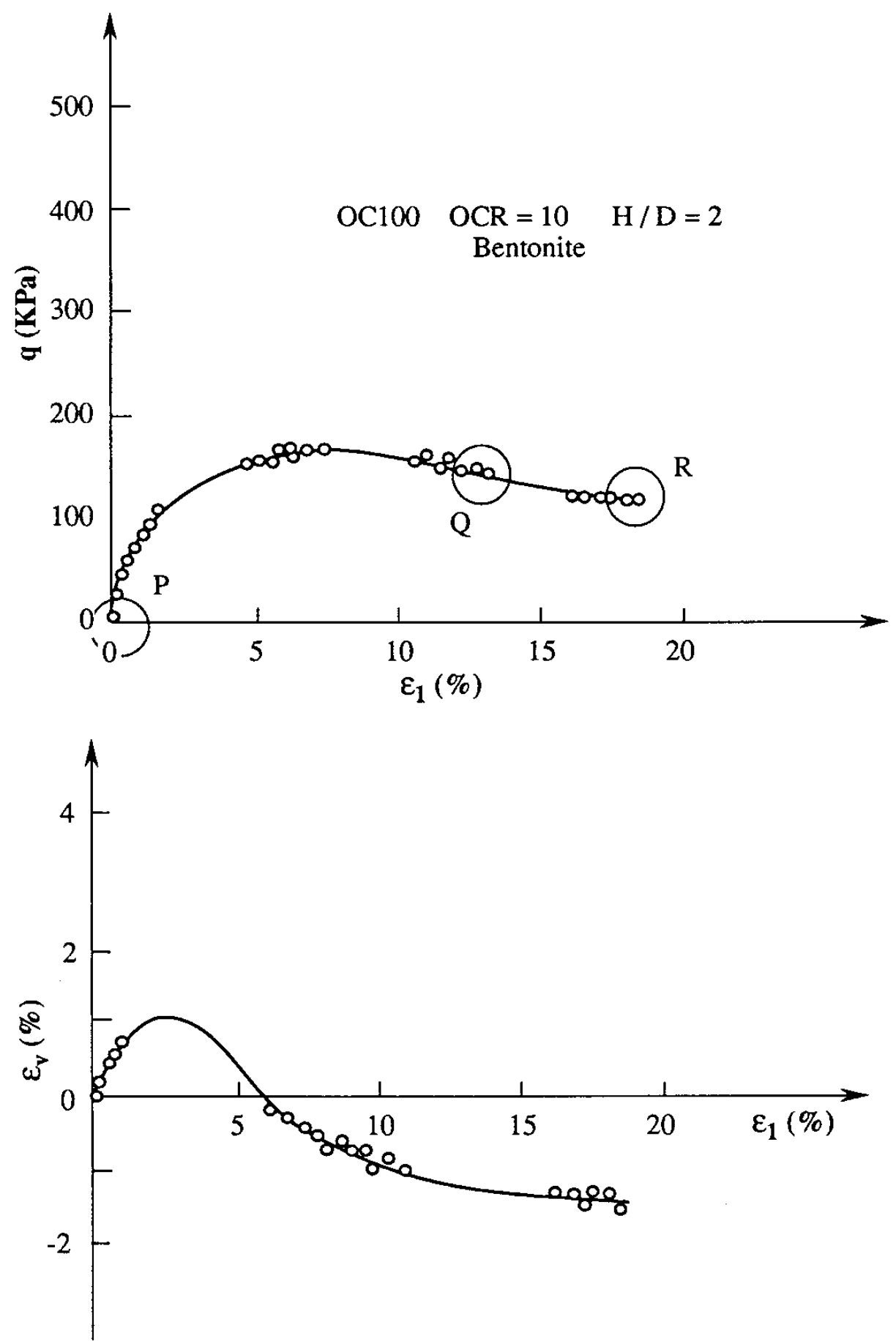

Figure 9. Drained triaxial test on over consolidated bentonite.

aggregates and more generally a decrease in the particle size. Figure 13 corresponds to a section selected inside the shear band which is visible on the photos. Several photos taken in different zones along the shear band lead to the same conclusions. The orientation of the particles next to the failure surface is parallel to the direction of the shear band. In comparison with the others parts of the samples, the mean size of the particles in the zone of failure is smaller and the size of the particles is less variable. This means that strain localization leads to large displacements but also to large rotations of the particles in the shear band, producing two consequences: firstly the creation of very large anisotropy of the structure in the central part of the band in 


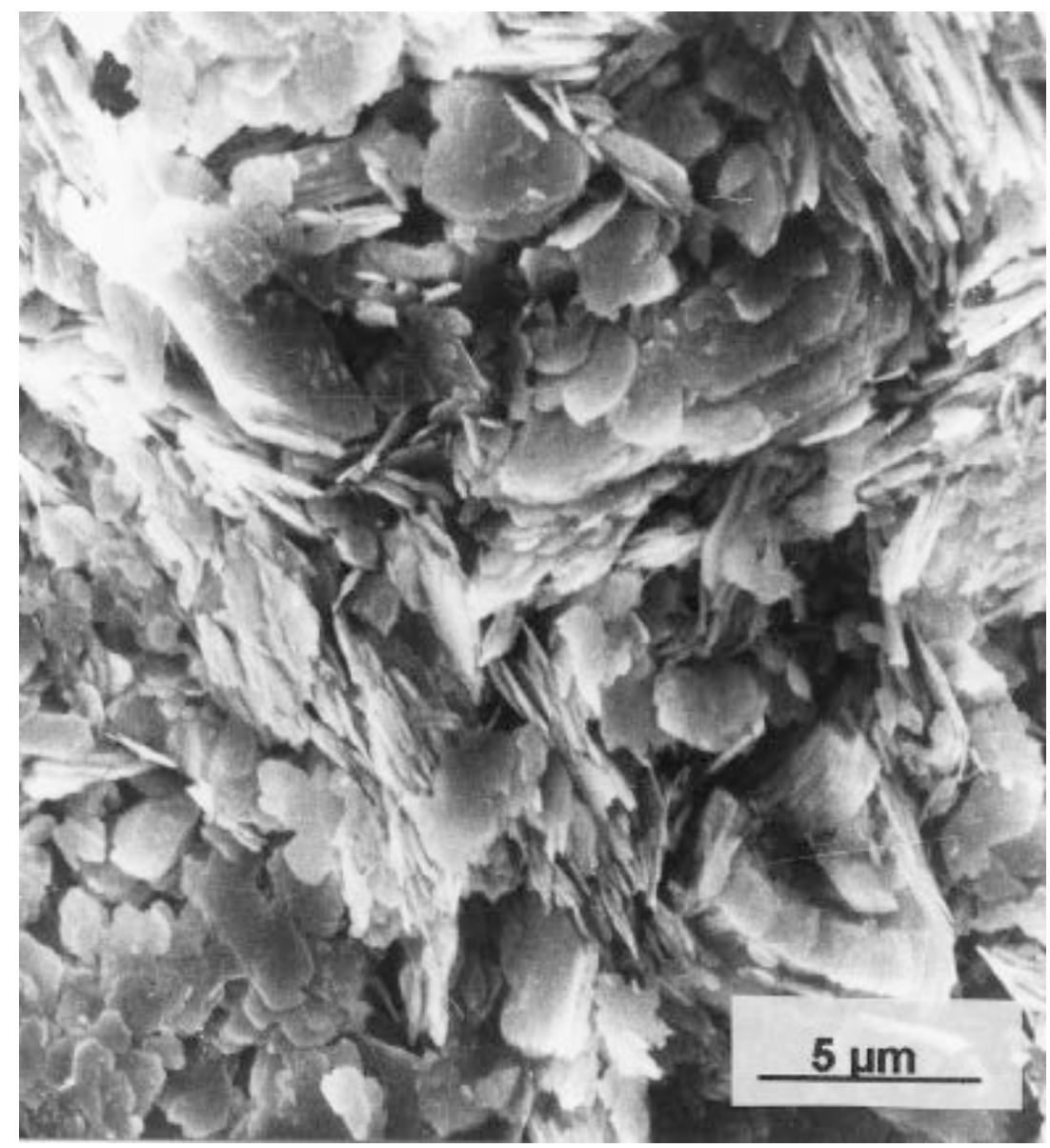

Figure 10. Observation of a kaolinite specimen isotropically consolidated at $300 \mathrm{kPa}$ (point A).

a narrow zone along the failure surface and, secondly, the breaking of aggregates and even particles in this zone.

The observation point $\mathrm{E}$ and $\mathrm{F}$ (Figure 7) correspond to drained triaxial tests on overconsolidated samples $(\mathrm{OCR}=10)$ sheared up to axial strains of 6 and 17.4 per cent, respectively. The two points belong to the dilatant domain and have void ratios higher than the initial void ratio. The same conclusion as before can be drawn from the observations in Figure 14: on a vertical plane we can see a progressive reorientation of the particles forming an oriented structure. The initial state (point D) has already been characterized by a decrease in particle size, compared to the initial point A for normally consolidated samples. This phenomenon continues during triaxial loading and at point $\mathrm{F}$, the big aggregates have disappeared almost completely. Therefore, rupturing of aggregates (as well as of smaller particles) does take place.

\section{RESULTS OBTAINED ON BENTONITE}

We have analysed samples of bentonite subjected to the same kinds of mechanical loading. The observations made during isotropic consolidation (point $\mathrm{K}, \mathrm{P}$, and $\mathrm{I}_{\mathrm{b}}$ ) indicate a progressive increase in density due to a void ratio decrease. The particle size remains homogeneous and, contrary to the results obtained with kaolinite, we do not see particles concentrating to form big aggregates. Big voids still exist at point $\mathrm{K}(0.3 \mathrm{MPa})$ and $\mathrm{P}(1 \mathrm{MPa})$, but at point $\mathrm{I}_{\mathrm{b}}$ 

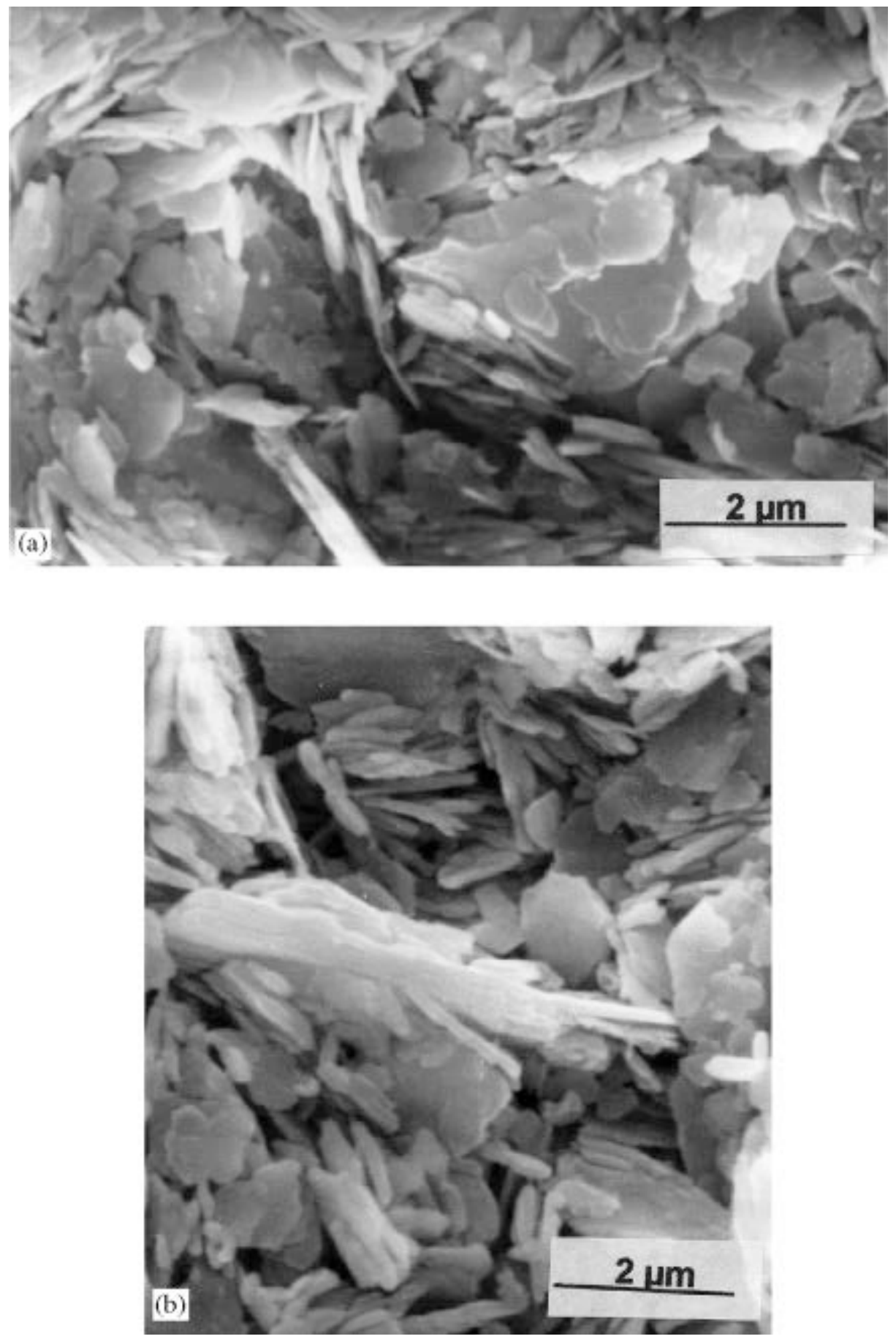

Figure 11. Observation of a kaolinite specimen isotropically consolidated at $1 \mathrm{MPa}$ : (a) horizontal plane, (b) vertical plane.

(6 $\mathrm{MPa})$, porosity is considerably lower and thus the voids are much smaller. The structure is isotropic and the arrangement of the particles is the same in both horizontal and vertical planes (Figure 15).

One-dimensional consolidation tests (points $\mathrm{O}_{\mathrm{b} 1}, \mathrm{O}_{\mathrm{b} 2}, \mathrm{O}_{\mathrm{b} 3}$ in Figure 5) are characterized by a strongly marked orientation of the particles in vertical planes. Due to the particularly long and flexible shape of bentonite particles, the possibility of reorientation is higher and hence the observations obtained at high consolidation stresses show a very high degree of the 

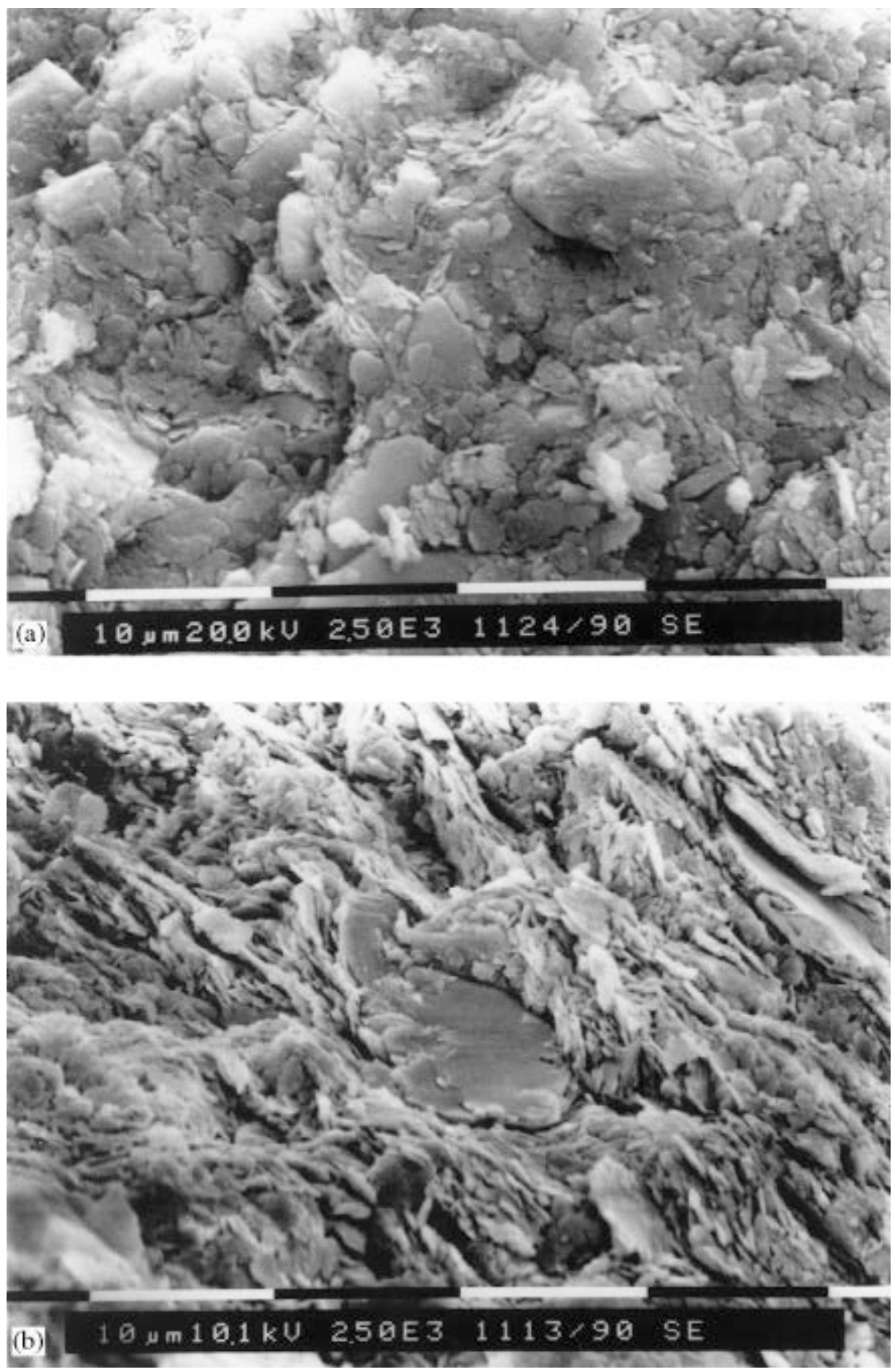

Figure 12. Observation of a kaolinite specimen: one-dimensional consolidation of $6.3 \mathrm{MPa}$ (point $\mathrm{O}_{\mathrm{K} 3}$ ): (a) horizontal plane, (b) vertical plane.

structural anisotropy in vertical planes. We observe also a decrease in particle size due to breakage, deformation and disintegration of the stacks of flakes as in the case of kaolinite (Figure 16).

Triaxial tests on normally consolidated samples (points L M, N) and overconsolidated samples (points $\mathrm{Q}$ and $\mathrm{R}$ ) also reoriented particles in vertical planes, but these phenomena are less pronounced and are visible mainly at large strain (points $\mathrm{M}, \mathrm{N}, \mathrm{R}$ ), accompanied by a decrease in particle size (Figure 17). 

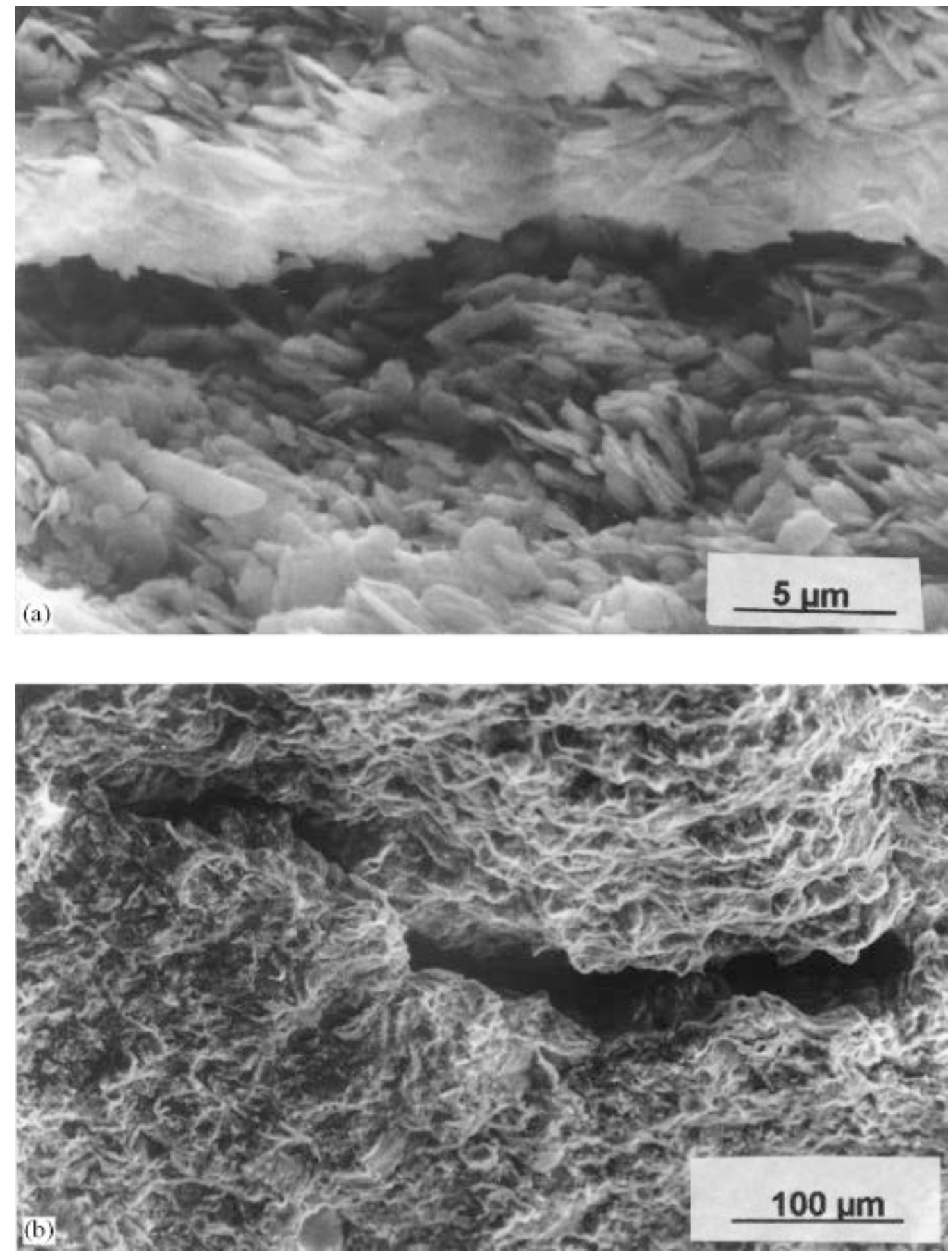

Figure 13. Observation of a kaolinite specimen submitted to a drained triaxial test up to $\varepsilon_{1}=19.5$ per cent (point C): (a) horizontal plane, (b) vertical plane.

\section{QUANTITATIVE ANALYSIS OF CLAY STRUCTURE EVOLUTION}

\section{Evolution of shape, size and concentration of clay particles}

The photos obtained by the SEM technique permitted us to focus our study on quantitative measuring of the evolution of clay structure elements, mainly of aggregates and single particles. However, this was possible only for the kaolinite because the shape of the bentonite particle was too complicated for our kind of analysis. 

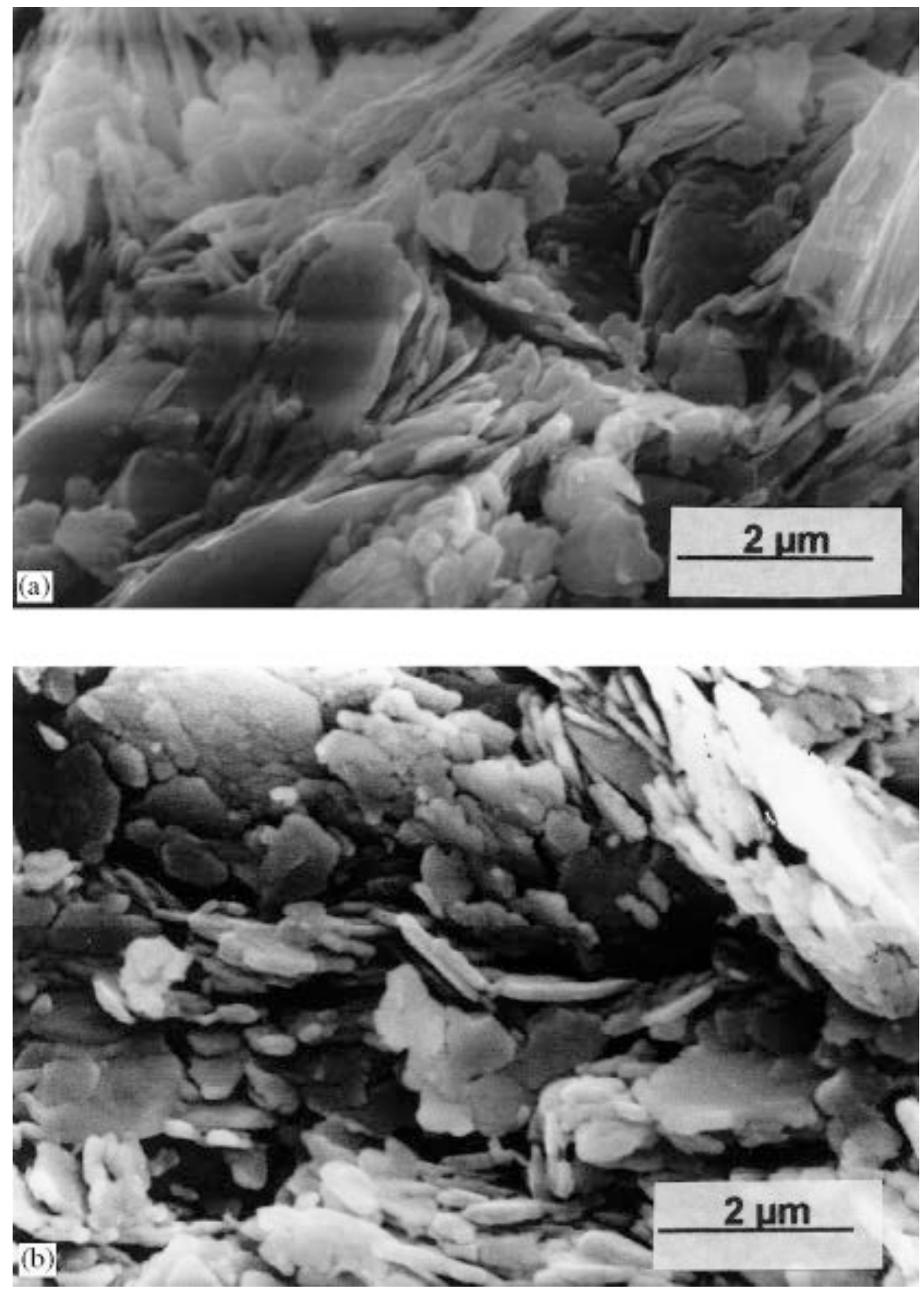

Figure 14. Observation of an over consolidated kaolinite specimen submitted to a drained triaxial test up to $\varepsilon_{1}=17.4$ per cent (point F): (a) horizontal plane, (b) vertical plane.

Our analysis was based on the following three parameters:

1. $I_{\mathrm{f}}$, the shape index, is the value of the ratio between the length $(A)$ and the width $(B)$ of the individual particle element or individual aggregate element. It is sometimes also called aspect ratio.

2. $S_{\mathrm{a}}$, the mean surface, is measured by considering the element as an ellipse: $S_{\mathrm{a}}=\pi A \mathrm{~B} / 2$.

3. $D_{\mathrm{p}}$, the particle concentration, represents the number of individual particles by surface unity expressed in $\mu \mathrm{m}^{2}$.

\section{Shape evolution}

The histograms of the shape index (Figure 18) allow us to conclude that the increase of the axial strain during loading creates an increase of the mean value of the shape index. The minimum 


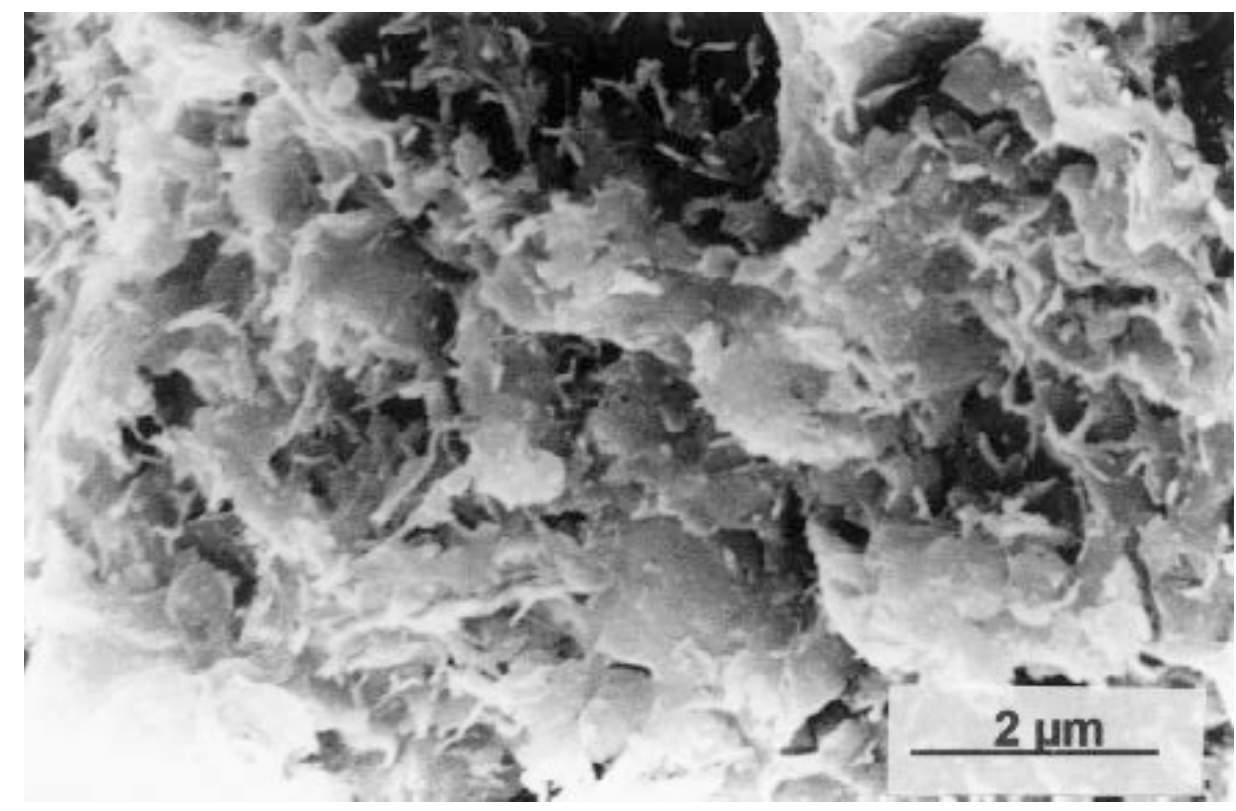

Figure 15. Observation of a bentonite specimen isotropically consolidated at $6 \mathrm{MPa}$ (point $I_{\mathrm{b}}$ ).

value of $I_{\mathrm{f}}$ is 1 for round (or square) particles and an increase of $I_{\mathrm{f}}$ signifies that the shape becomes more angular. The value of $I_{\mathrm{f}}$ is in general larger on a vertical plane than on a horizontal plane. This result was obtained from both triaxial and one-dimensional consolidation tests. However, the evolution of $I_{\mathrm{f}}$ on a horizontal plane was found to be less important in the case of one-dimensional tests. This is due to the fact that the particles rotate during loading and end up in a flat position on a horizontal plane; this phenomenon becomes pronounced during onedimensional testing (Figures 20 and 21).

\section{Size evolution}

The histograms representating $S_{\mathrm{a}}$ show at first a high degree of scattering of the values because of the initial grain distribution and the sedimentation process which creates aggregates of different sizes (Figure 19). The evolution of the histograms corresponding to different loading steps shows a decrease in size during loading, accompanied by a decrease in scattering. This indicates that there is a breakage of the aggregates and that the biggest ones split into smaller elements at first, leading to a more homogeneous size distribution. At large deformations, the big aggregates disappear almost completely. These observations can be made for both triaxial and onedimensional tests (Figures 20 and 21) and have been also reported by various investigators [13].

If we relate the evolution of the shape to that of the size, we can conclude that the breakage of the aggregates into smaller particles affects mainly the width of the aggregates. Delamination occurs along the plane direction of the individual particles constituting the aggregates. During the sedimentation process, the particles agglomerate to create an aggregate. Their surfaces of contact, however, remain the weakness zones within the aggregates which, upon being subjected to shear forces, will be the first to break.

\section{Evolution of particle concentration}

Particle concentration is not only connected to the density of particle assembly, which is equal to the density of the sample, but is also connected to the shape and the size of the particles. If these 


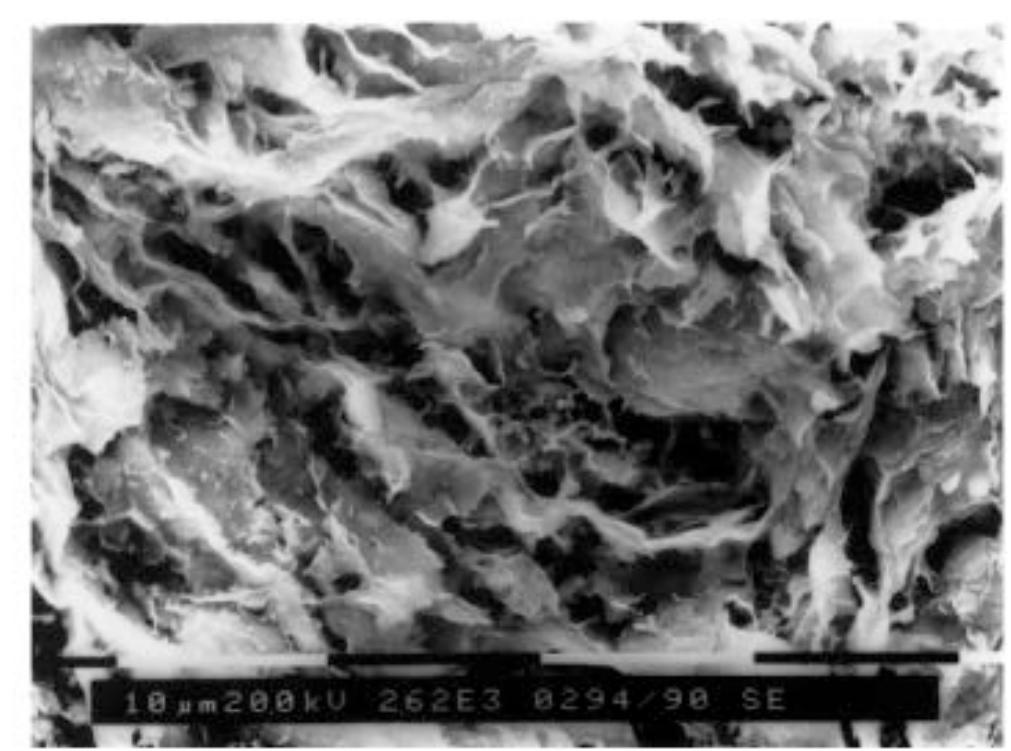

(a)
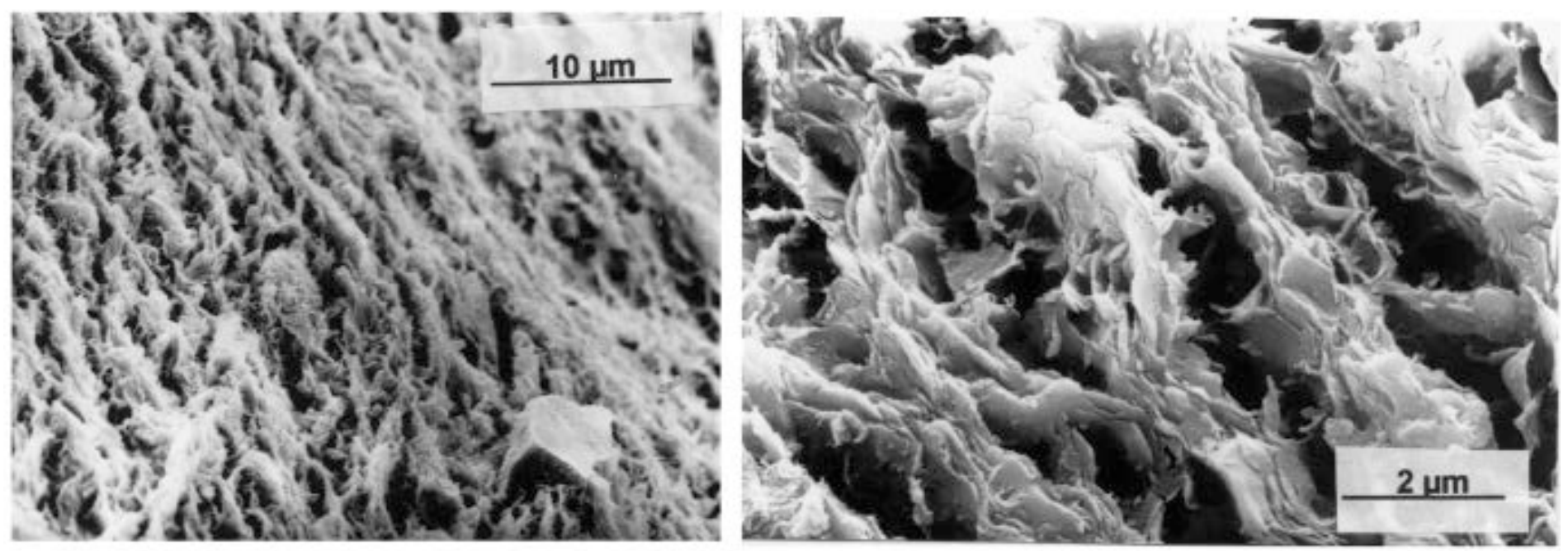

(b)

Figure 16. Observation of a bentonite specimen: one-dimensional consolidation at $1 \mathrm{MPa}$ (point $\mathrm{O}_{\mathrm{b} 2}$ ): (a) horizontal plane, (b) vertical plane.

two parameters remain equal, we can then assume that the evolution of particle concentration is the same as that of sample density. However, as seen before, a significant change in shape and size takes place during loading. In general, an increase of axial strain in all tests created an increase of the mean value of the particle concentration which could be interpreted as being chiefly a consequence of particle breakage (Figures 20 and 21).

\section{Evolution of particle orientation}

In order to study particle orientation, we tried to construct rose diagrams from photos obtained with the SEM. In connection to each photo, the plane was divided into a given number of quadrants (each of them equal to $15^{\circ}$ ). We then counted the number of particles from which the long axis (length $A$ ) was oriented within a given quadrant. By dividing this number by the total number of particles, we obtained a percentage of particles for a given orientation, which allowed 


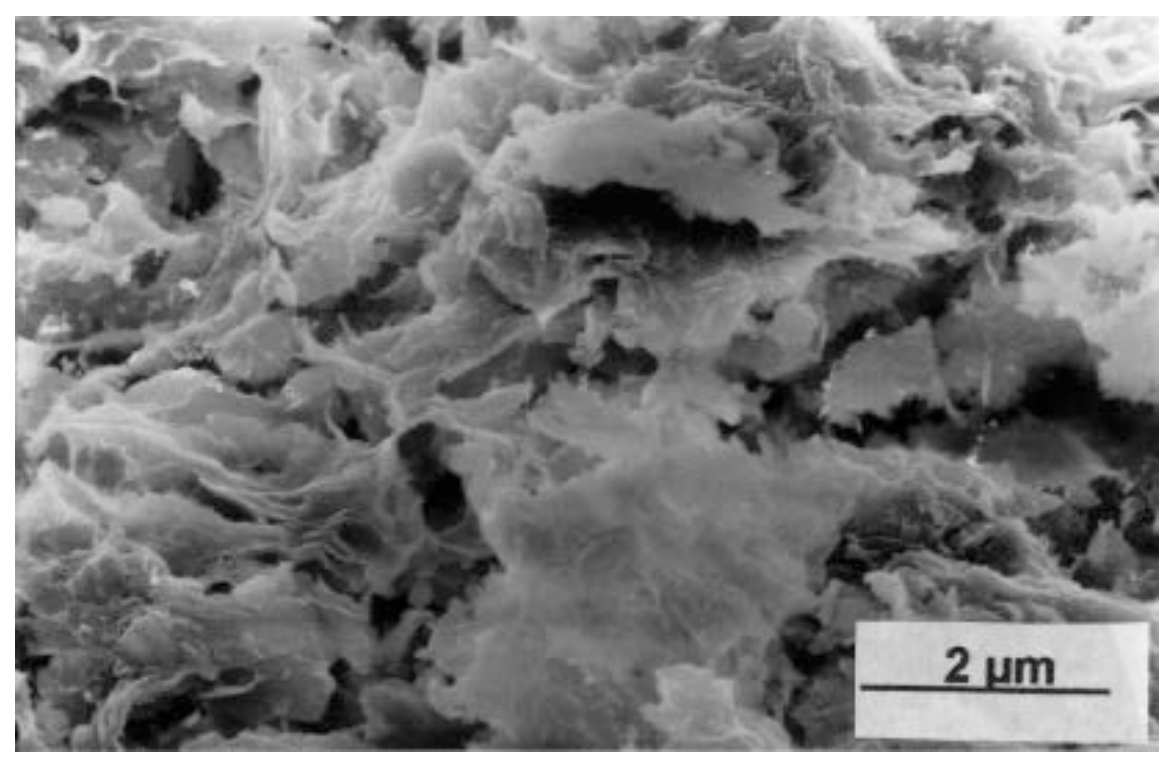

Figure 17. Observation of a bentonite specimen submitted to a drained triaxial test up to $\varepsilon_{1}=17$ per cent (point $\mathrm{M}$ ).

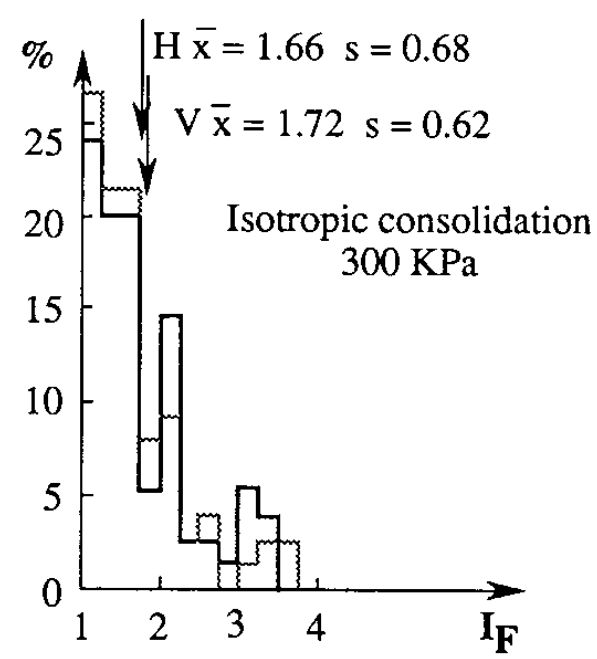

Triaxial test NC 300

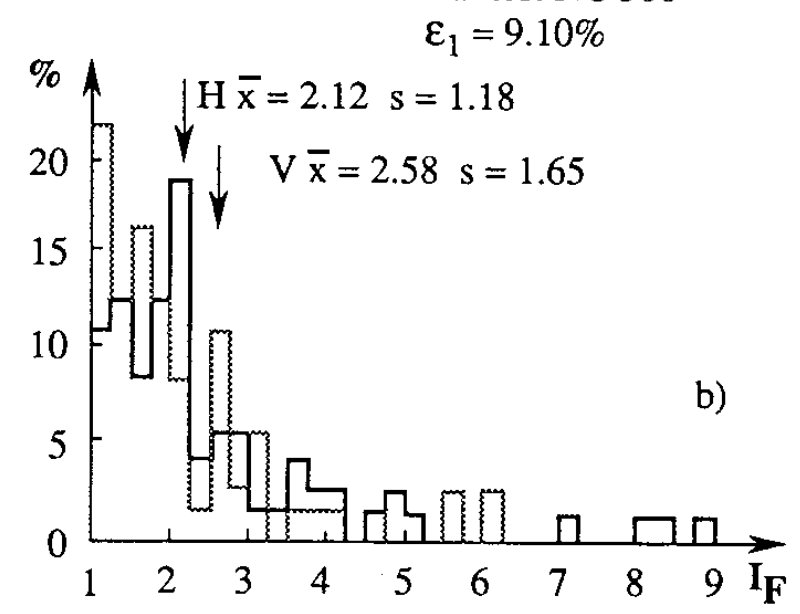

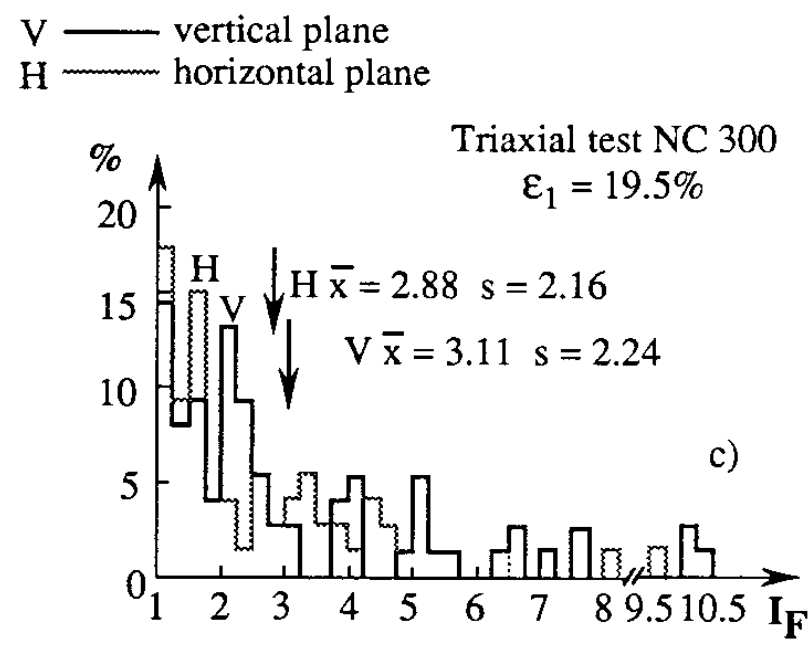

Triaxial test NC 300 $\varepsilon_{1}=19.5 \%$ in the localised zone

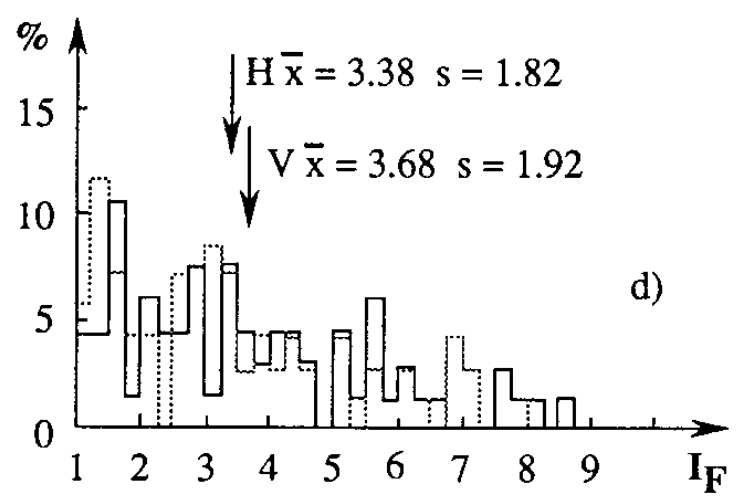

Figure 18. Shape index histograms of kaoline specimen for drained triaxial tests. 


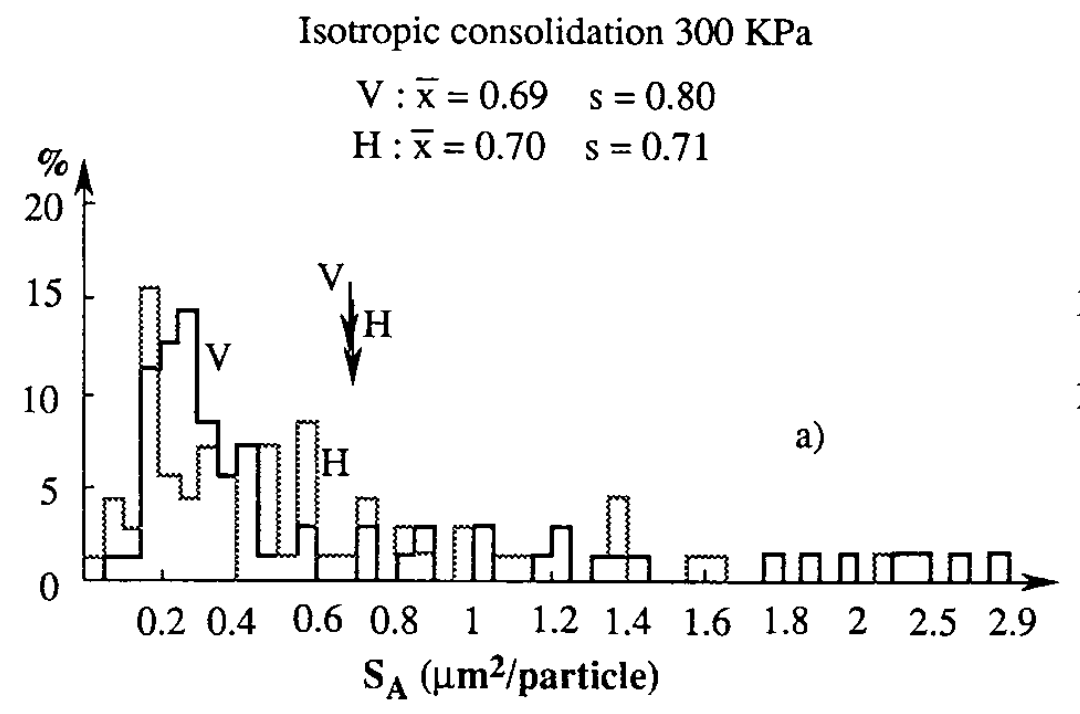
Triaxial test NC 300, EPS $1=19.5 \%$ in the localised zone
$\mathrm{V}: \overline{\mathrm{x}}=0.28 \quad \mathrm{~s}=0.17$
$\mathrm{H}: \overline{\mathrm{x}}=0.29 \quad \mathrm{~s}=0.22$

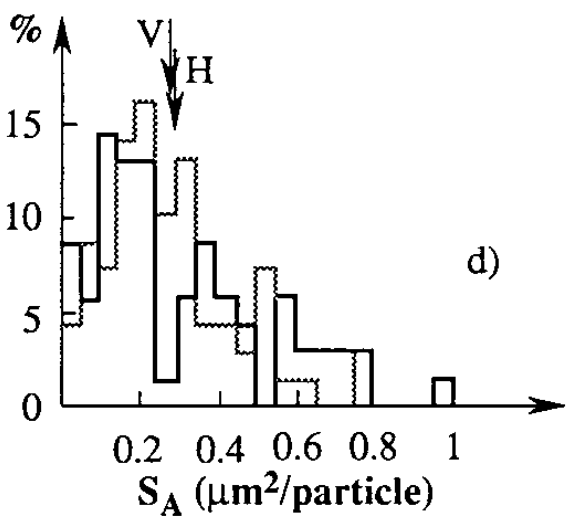

$\mathrm{V} \longrightarrow$ vertical plane
$\mathrm{H}-$ horizontal plane

Triaxial test NC 300, EPS $1=9.1 \%$

$$
\begin{array}{cc}
\mathrm{V}: \overline{\mathrm{x}}=0.42 & \mathrm{~s}=0.35 \\
\mathrm{H}: \overline{\mathrm{x}}=0.51 & \mathrm{~s}=0.47
\end{array}
$$

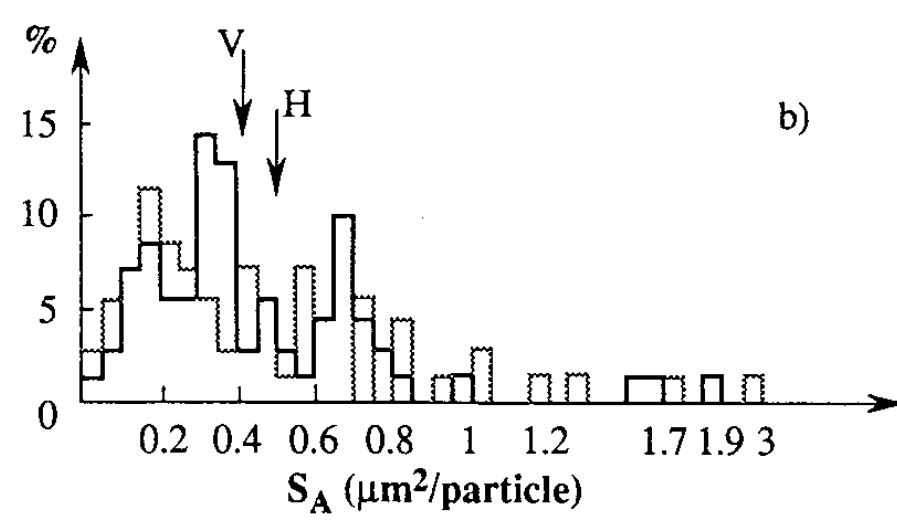

Triaxial test NC 300, EPS $1=19.5 \%$

$$
\begin{array}{ll}
V: \bar{x}=0.35 & s=0.36 \\
H: \bar{x}=0.38 & s=0.35
\end{array}
$$

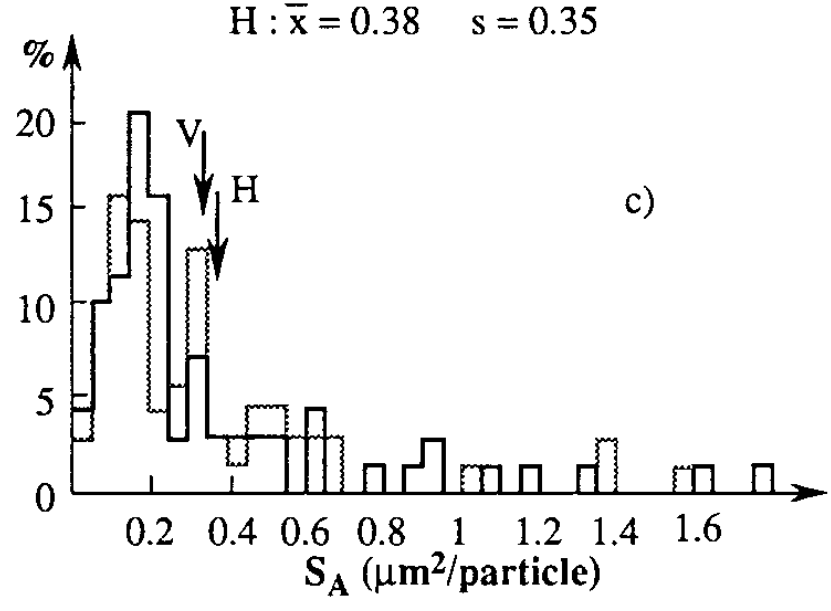

Figure 19. Mean surface histograms of kaolinite specimen for drained triaxial tests.

us to drawn a radius of the same orientation starting from the centre with a length proportional to this percentage. With this construction, we could see that, for any given isotropic structure, all the radii would have the same length (equal in our case to $\frac{1}{12}=0.083$ ) and they will define a circle. Each rose diagram was constructed by superposing the results obtained from ten photos at the same mechanical state. For example, in Figures 22 and 23, we could see that isotropic consolidation in kaolinite and bentonite led to rose diagrams of circles in both horizontal and vertical planes. The presence of some peaks at different orientations corresponds to the rupture of big aggregates which occurred as a consequence of delamination along particle planes while the individualized particles stayed parallel to each other. We could see that the diagrams corresponding to large consolidation stresses were more regular due to more systematic ruptures of the aggregates of different sizes.

The evolution of the rose diagrams along triaxial loading show an increasing difference between horizontal and vertical planes, with the existence of a privileged direction in the latter 

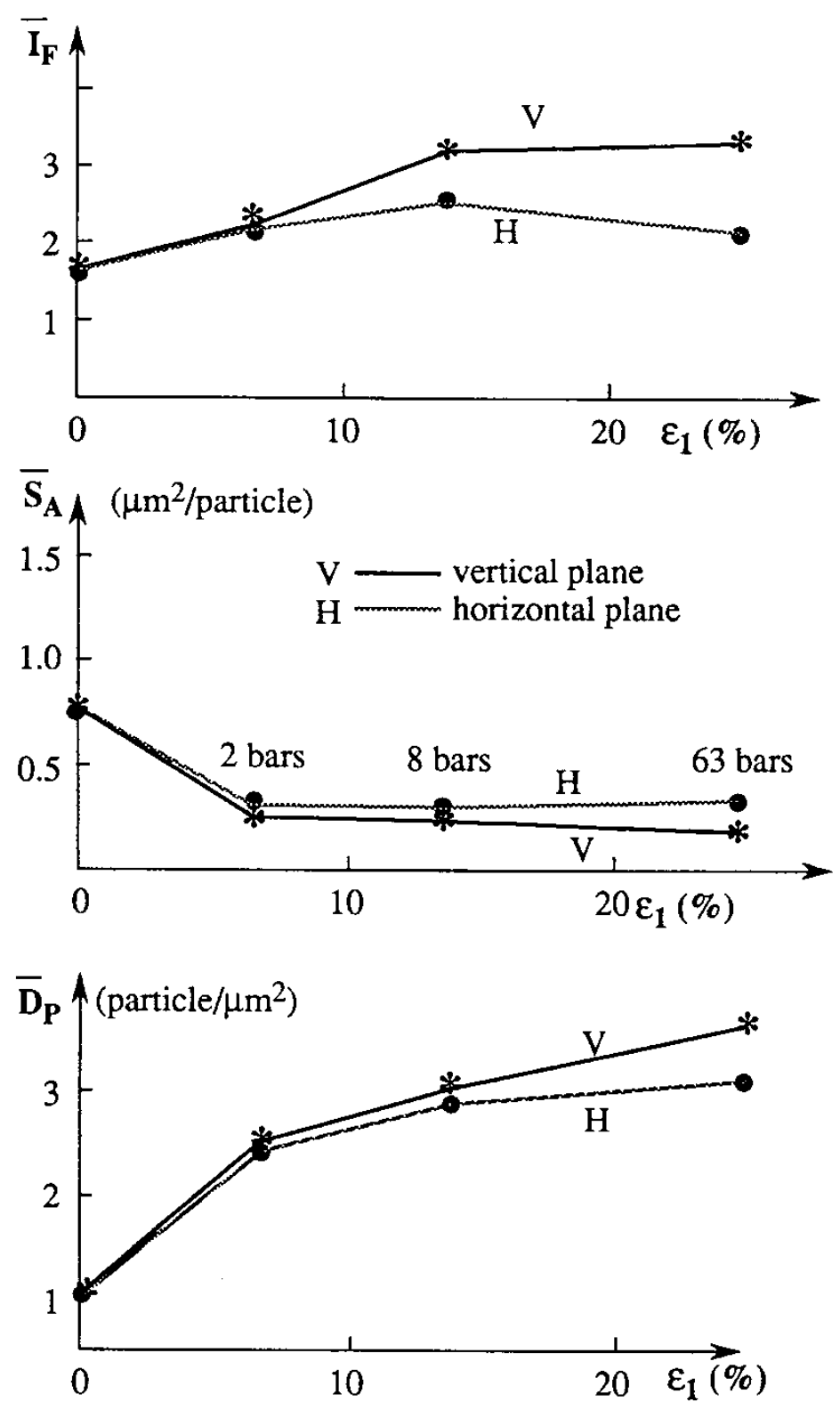

Figure 20. Evolution of shape index, mean surface and particle concentration as a function of the major principal strain during drained triaxial tests.

case that corresponds to the direction of loading. For example, in the case of kaolinite, an axial strain of 20 per cent at the end of the test created a reorientation of the particles in the direction perpendicular to the vertical axis which groups together 19-21 per cent of the particles (as opposed to 8.3 per cent for an isotropic structure). The same order of magnitude was obtained for the bentonite tested under the same conditions.

The most radical orientation was obtained with one-dimensional loading. For a vertical stress of $800 \mathrm{kPa}\left(\varepsilon_{1}=13.75\right.$ per cent), the percentage of particles oriented perpendicular to the vertical axis was $I_{\max }=25$ per cent and reached 30 per cent when the vertical stress was equal to $6.3 \mathrm{MPa}$. The results obtained with the bentonite was even more remarkable: for a vertical stress of $1 \mathrm{MPa}$, the same percentage was equal to 31 percent and went up to 33 percent for a vertical stress equal to $6.3 \mathrm{MPa}$ (Figure 23).

We obtained therefore a very strong structural anisotropy due to large reorientation of particles in the direction perpendicular to the direction of loading. 


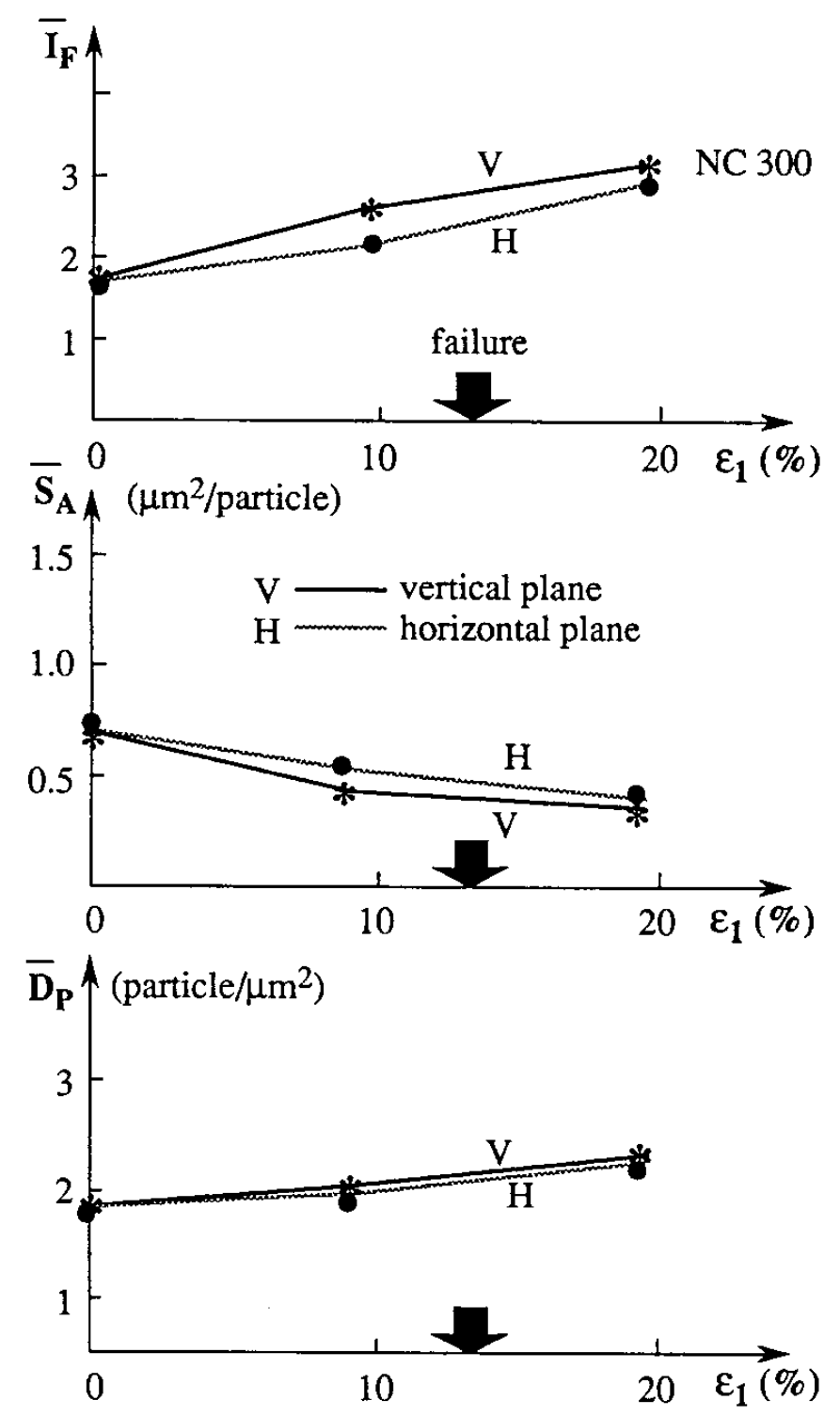

Figure 21. Evolution of shape index, mean surface and particle concentration as a function of the major principal strain during one-dimensional consolidation tests.

Some analysis from X-ray diffraction confirmed the existence of induced anisotropy during triaxial loading. Figure 24 presents Debye-Scherres diagrams on a kaolinite samples in two different states: initial slurry and normally consolidated sample subjected to a triaxial test up to 17 percent of axial strain. The first ring starting from the centre corresponds to the one of the kaolinite $(d=7.15 \AA)$. In the case of the slurry, it has a homogeneous intensity indicating an isotropic structure, while for the other we can observe a variation in intensity which corresponds to a very definite anisotropy in the clay structure.

\section{EVOLUTION OF THE PORES}

Mercury intrusion porosimetry was applied to different samples of bentonite and kaolinite submitted to various loading history. Contrary to the SEM which characterizes the organization of the solid phase, we are investigating here the pores and their evolution during mechanical 


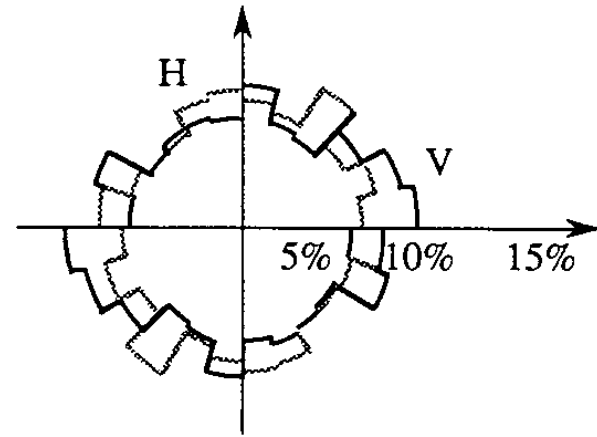

Isotropic consolidation $300 \mathrm{KPa}$

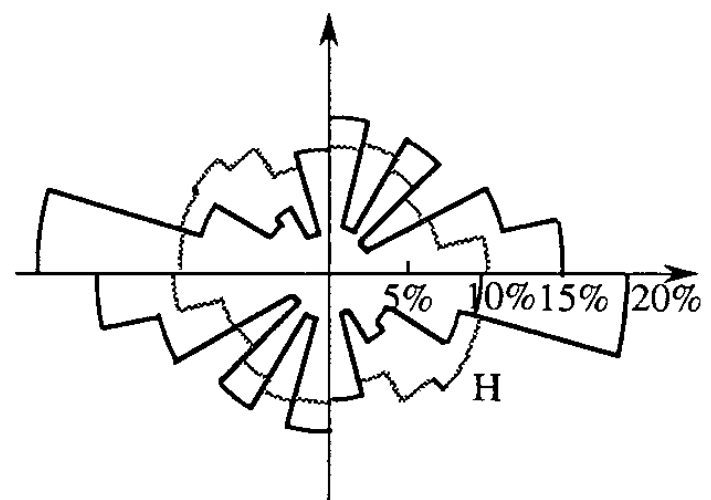

Triaxial test $\varepsilon_{1}=19.5 \%$

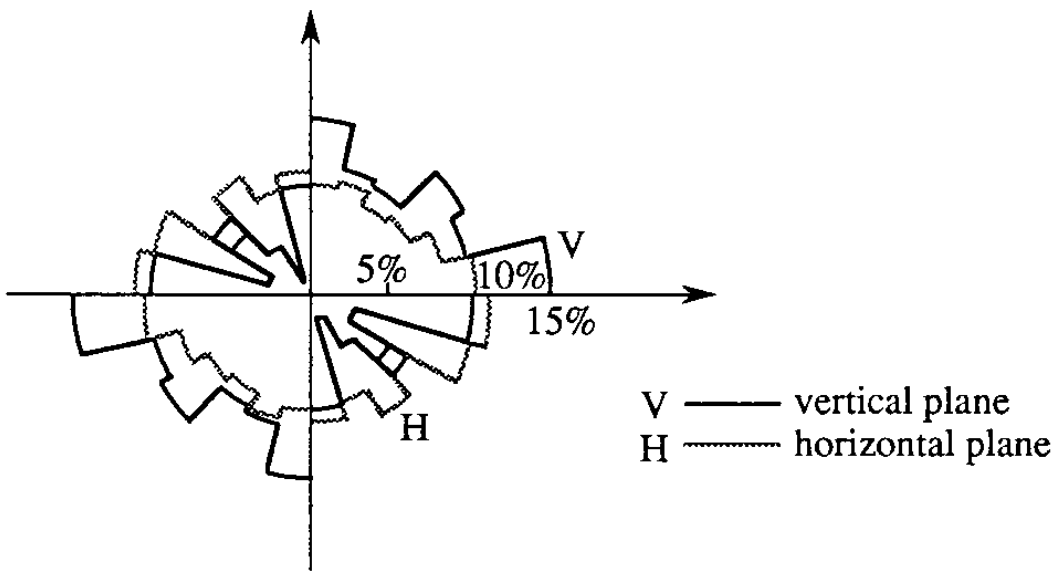

Triaxial test $\varepsilon_{1}=9.1 \%$

Figure 22. Rose diagrams of kaolinite particle orientation after drained triaxial tests.

Isotropic consolidation $6 \mathrm{MPa}$

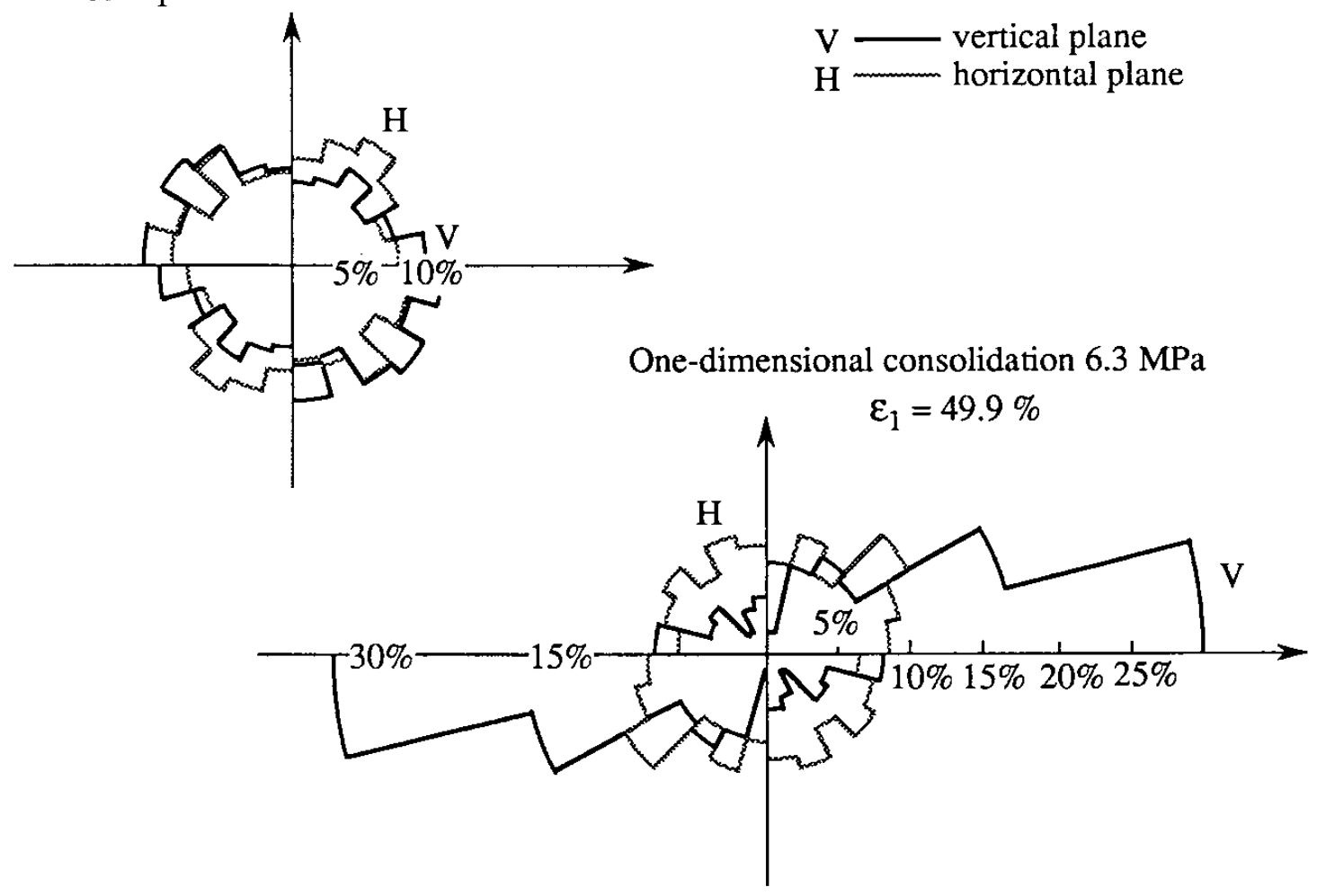

Figure 23. Rose diagrams of bentonite particle orientation after one-dimensional consolidation tests. 

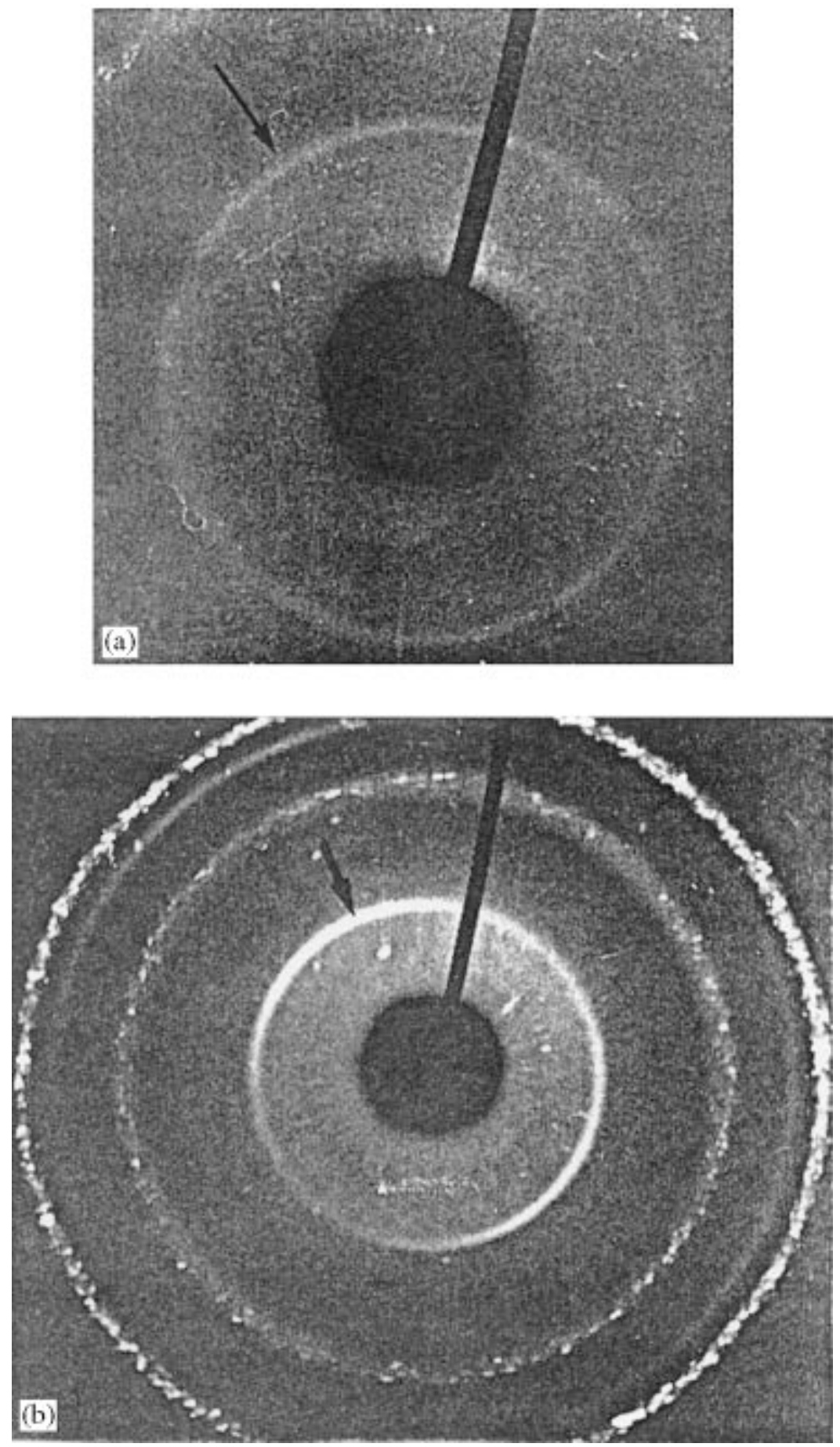

Figure 24. X-ray diffraction tests on kaoline specimen: (a) initial slurry, (b) triaxial test up to $\varepsilon_{1}=17$ per cent.

loading. The results can be accounted for by two curves:

1. The cumulative pore volume as a function of pore diameter.

2. The derivative of the previous curve as a function of pore diameter.

Some results obtained on the bentonite are presented in Figure 25. Two major groups of pores emerged after an isotropic or one-dimensional consolidation at small stresses: one centres around $8 \mu \mathrm{m}$ and the other around $10 \mathrm{~nm}$. The first group corresponds to the inter-aggregate pores while the second is related to the inter-particulate pores. 

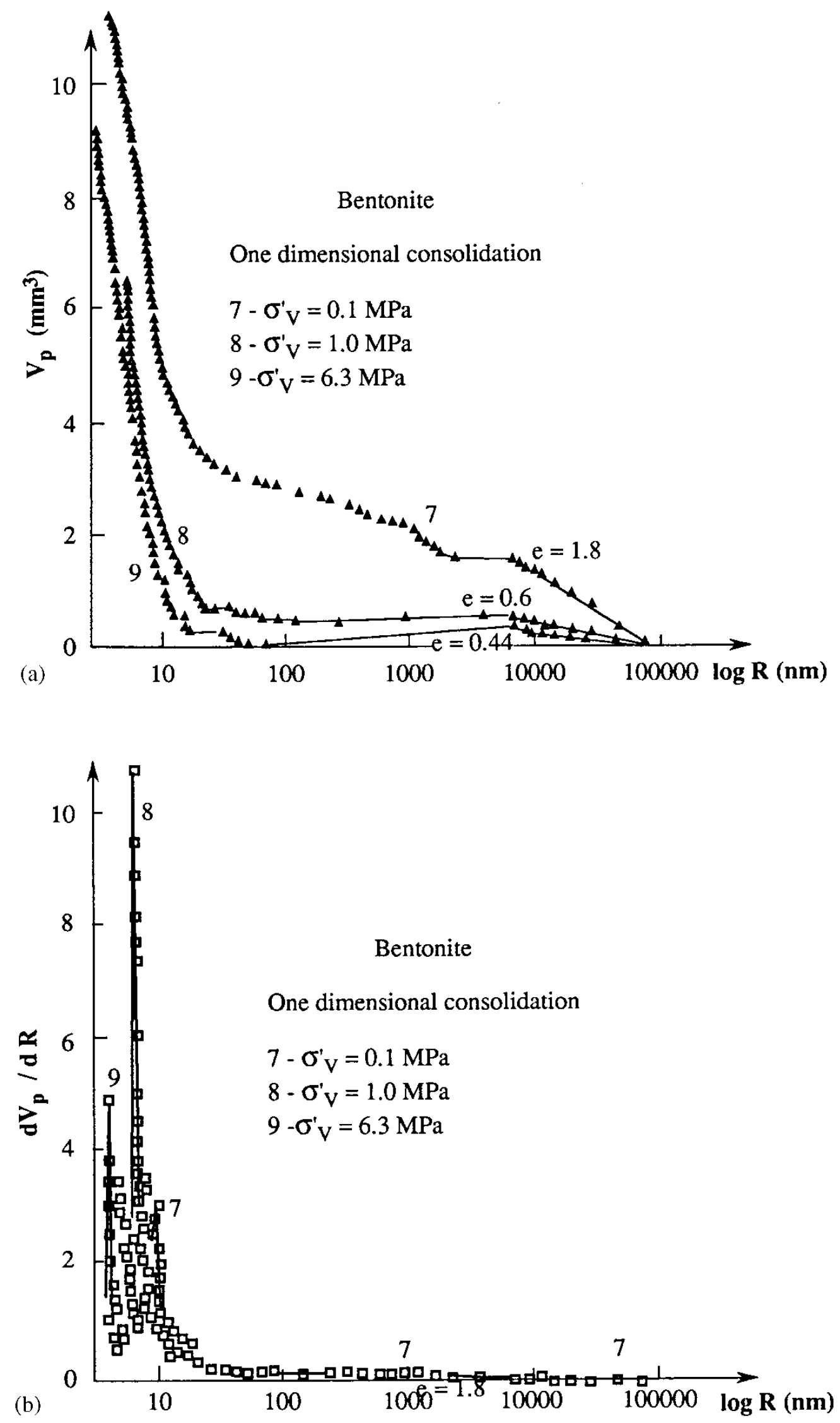

Figure 25. Mercury porosimetry results for bentonite specimen after one-dimensional loading: cumulative pore volume as a function of pore diameter. 
The number of big pores corresponding to inter aggregate pores progressively decreases when consolidation stress increases, while the dimensions of small pores, corresponding to interparticulate pores, become progressively smaller down to $4 \mathrm{~nm}$ for high consolidation stress (6.3 $\mathrm{MPa}$ for the vertical stress during one-dimensional consolidation). At these high stresses, the big pores nearly disappear. This phenomenon corresponds to significant change in void ratio at the scale of the sample and in the mechanical properties at a macroscopic level. The compressibility Index $C_{\mathrm{C}}$ decreases from 1.51 for small stresses to 0.23 for high stresses, due to the disappearing of the big pores which leads to an increase in the stiffness of the clay structure.

The results of the mercury porosimetry show that during mechanical loading the change in the pore geometry is noticeable mainly because of the progressive disappearing of the big pore family (around $8 \mu \mathrm{m}$ ). When, by using the SEM technique, we examined the solid phase, we could conclude that significant breakage of the biggest aggregates occurred under the same mechanical conditions. These two phenomena are completely connected and the simultaneous use of these two techniques offer us complementary ways of reaching the same conclusions regarding the behaviour of the clay at the scale of particles.

\section{MICRO-ORGANIZATION AT THE LEVEL OF LAYERS}

Observations at the scale of the crystals using TEM lead to the same conclusions as the ones obtained from the SEM. In particular we could follow the increase of the anisotropy of the structure during one-dimensional and triaxial tests in vertical planes, while the arrangement of the particles remained isotropic in a horizontal plane.

The number of layers which constitutes the tactoids can vary during the loading history of the samples. In general, the measured number of layers was somewhere between 50 and 80 . Within the tactoids, internal discontinuities as large as $10 \mathrm{~nm}$ in size could be observed, especially for small consolidation stresses. These micropores play an important role during the shearing or the consolidation process. Two major phenomena were observed. At large strains, there is a decrease in the volume of the micropores and the layers can becomes perfectly parallel, creating a stronger rigidity of individual particles. The micropores, and especially the bigger ones, can form a zone of weakness for the particles: at larger stresses or strains, a delamination of the particles, initiated at the level of these discontinuities inside the particles, could be observed (Figure 26).

This evolution at the scale of the tactoids is thus very similar to the one observed at the scales of the aggregates and it contributes to the evolution of the clay structure: development of anisotropy and changes in the dimension of the constitutive elements, aggregates and particles.

\section{INFLUENCE OF STRUCTURAL ANISOTROPY ON MECHANICAL PROPERTIES OF CLAY}

In order to quantify the anisotropy of the structure, we created a parameter $I_{\text {or }}$, called the orientation index, which was defined as follows: if $\mathrm{Q}$ is the zone of maximum orientation intensity $\mathrm{Q}$ (per cent) in a rose diagram, we would consider the neighbouring zones $\mathrm{P}$ and $\mathrm{R}$ and zone $\mathrm{L}$ directly perpendicular to $\mathrm{Q}$ and its neighbouring zones $\mathrm{K}$ and $\mathrm{M} ; I_{\mathrm{or}}$ will be the ratio between 


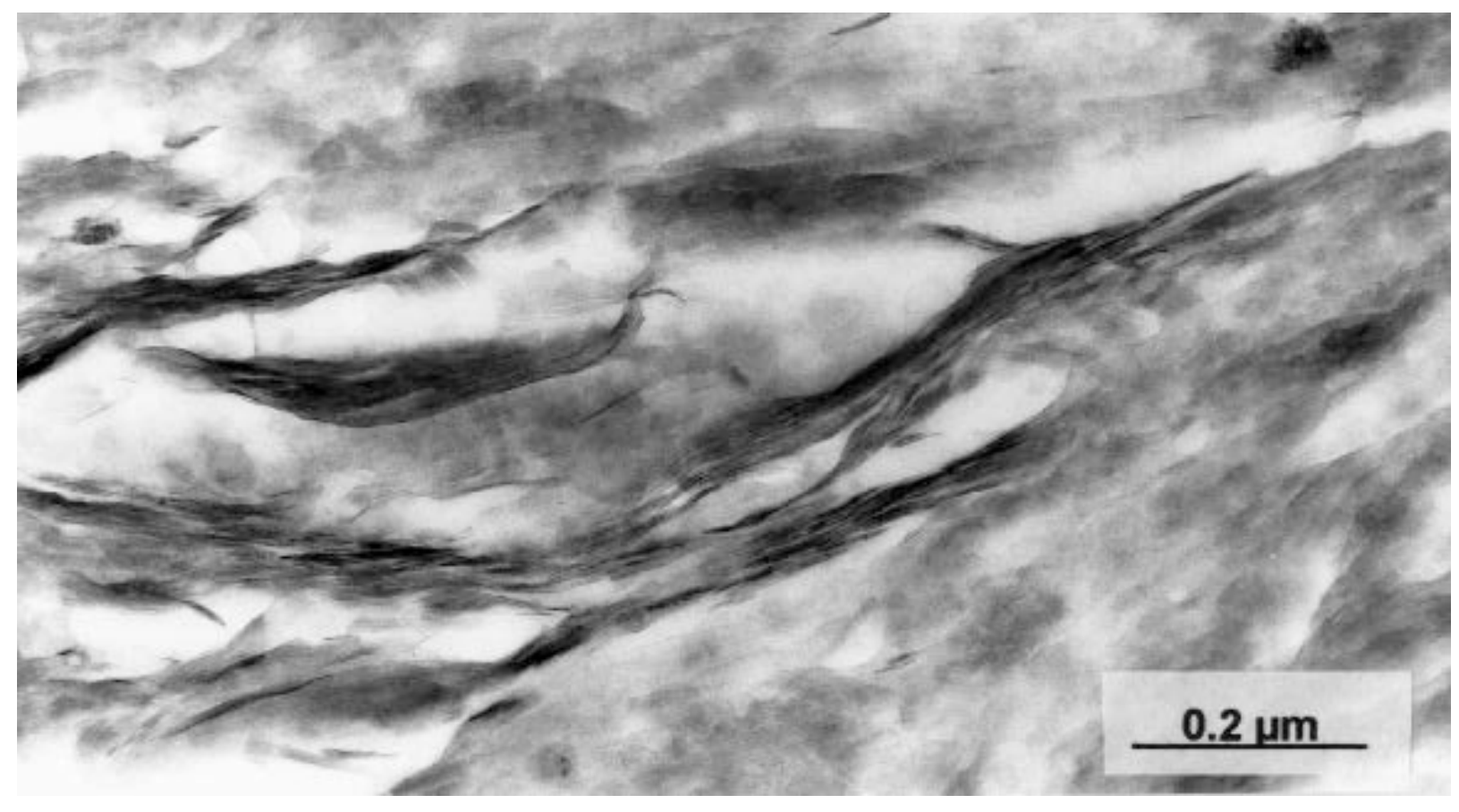

Figure 26. TEM observation of a bentonite particle.

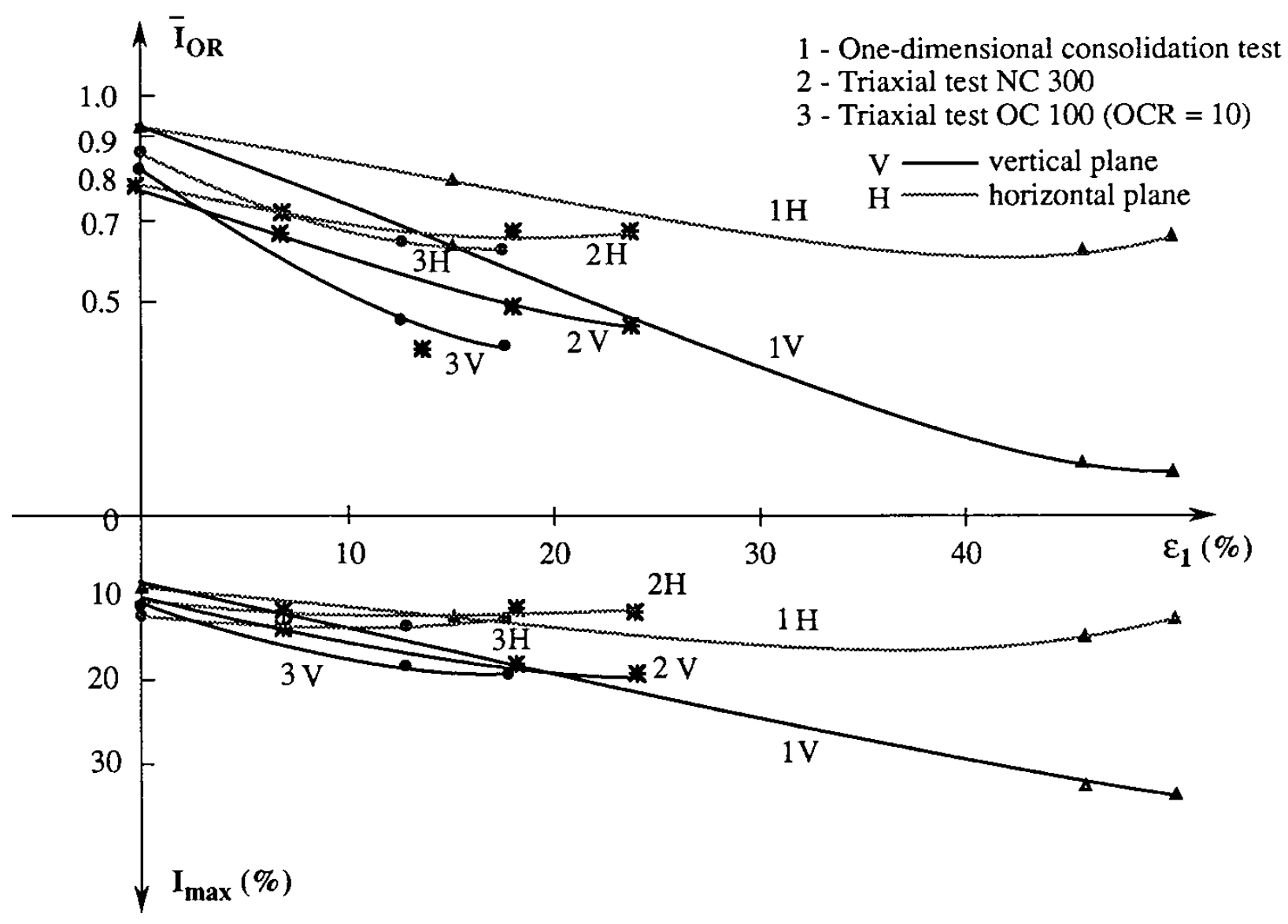

Figure 27. Evolution of bentonite particle orientations as a function of major principal strain.

$(\mathrm{K}$ (per cent $)+\mathrm{L}($ per cent $)+\mathrm{M}($ per cent $))$ and $(\mathrm{P}$ (per cent $)+\mathrm{Q}($ per cent $)+\mathrm{R}($ per cent $)) . I_{\text {or }}$ can vary from 1 for an isotropic structure to 0 for a perfectly anisotropic structure. Figure 27 shows an example of $I_{\text {or }}$ evolution during triaxial and one-dimensional loading in horizontal and vertical planes. 
We notice that on a vertical plane, a strong decrease of $I_{\text {or }}$ occurs when the axial strain increases. This is more significant in the case of one-dimensional loading because it expresses a progressive increase of the structure's anisotropy. We can also see a slight decrease of $I_{\text {or }}$ on a horizontal plane. This corresponds to what was said earlier about the rupture of aggregates into parallel particles. In that particular case, however, the decrease of $I_{\mathrm{or}}$ is small and tapers off quickly.

In order to analyse the effects of the structure anisotropy on mechanical properties, we performed two one-dimensional consolidation tests on kaolinite specimen, one up to $\sigma_{\mathrm{v}}^{\prime}=150 \mathrm{kPa}$ and the other up to $2.25 \mathrm{MPa}$. In the first case, $I_{\text {or }}=0.67$ and, in the second, $I_{\text {or }}=0.23$. Two samples were prepared, one in a vertical direction and another in a horizontal direction and they were subjected to a triaxial loading starting from a mean effective stress equal to the one existing at the end of each one-dimensional consolidation $\left(K_{0}=0.54\right)$ in order to avoid a significant change in the initial clay structure. The results are presented in Figure 28. We can see that for $I_{\text {or }}=0.67$ the horizontal and vertical samples are similar. In the case of a strong anisotropy $\left(I_{\mathrm{or}}=0.23\right)$, however, the specimen subjected to a triaxial loading in the direction of the previous loading which created anisotropy (vertical sample), has larger stiffness and larger strength than the one previously loaded in a perpendicular direction (horizontal sample). For example, the tangent modulus is 1.5 higher in the first case. The maximum strength is less affected, which indicates the influence of an induced anisotropy which has superimposed itself on the initial one. This phenomenon can also be observed on the evolution of the secant modulus which decreases more rapidly in the case of the vertical sample.

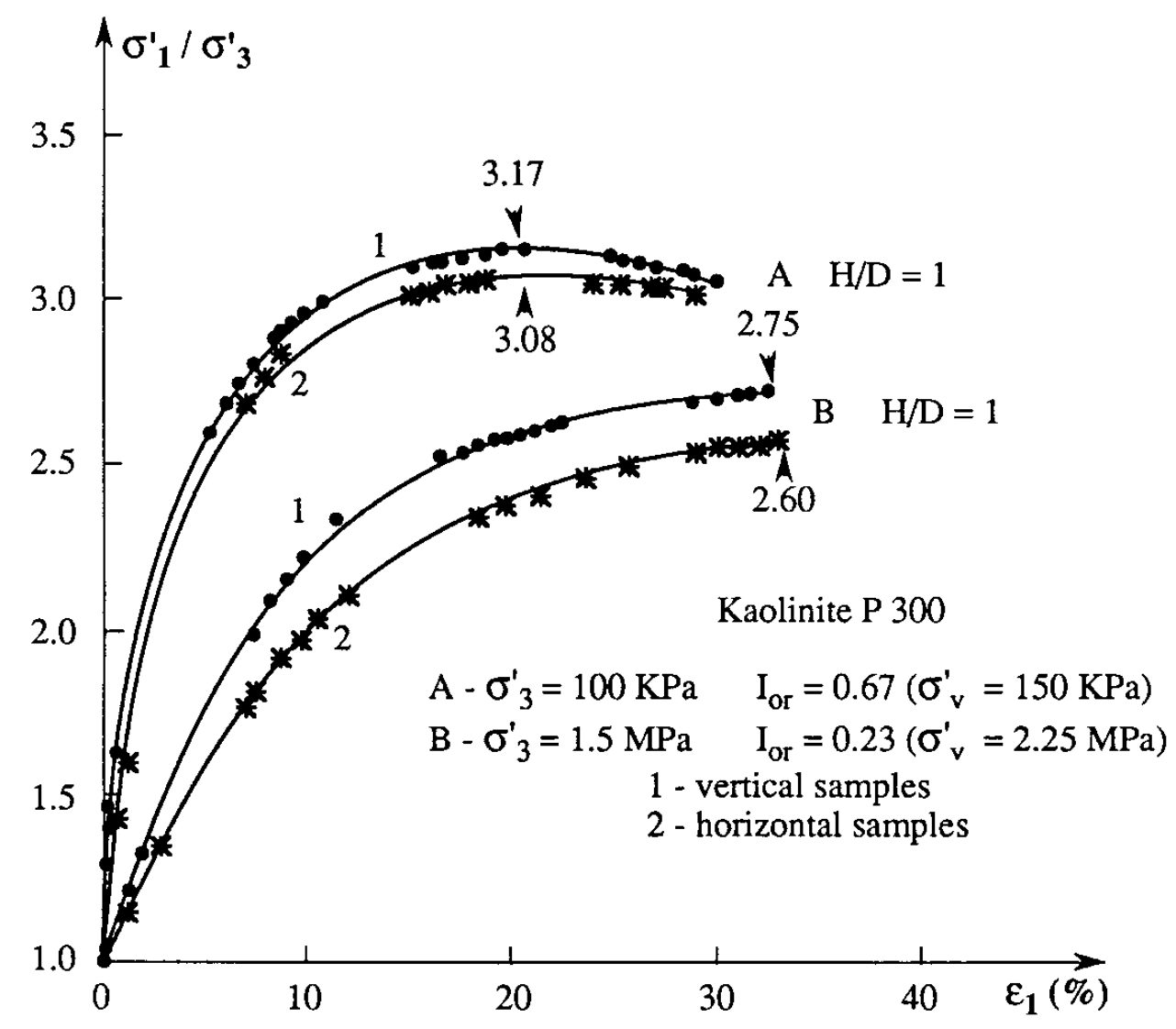

Figure 28. Influence of the structure anisotropy on the stress-strain relationship of kaolinite specimen during drained triaxial tests. 
Besides these differences due to the initial anisotropy, we also observe a difference in the stress-strain relations obtained at low and high consolidation stresses. At high stresses, the clay samples appeared to be more ductile and the maximum strength (expressed by the ratios $\sigma_{1} / \sigma_{3}$, or the friction angle) was lower. This is probably due to the effect of particle rupture during shearing. The same effect of grain crushing was obtained from the stress-strain relationship for other granular materials such as sands, gravels or glass balls. This phenomenon was widely studied in clay by Naskos [23].

Some three-dimensional triaxial tests were also performed on samples of normally consolidated kaolinite [24]. Initial anisotropy was created on isotropically consolidated samples by an axisymmetric drained compression up to a major principal strain of 5 per cent. The corresponding structure of the clay samples is similar to the one associated with point B in Figure 6 and is represented by the rose diagram in Figure 21. Figure 29 presents the results of five threedimensional tests.

We have two tests at $b=0\left(b=\left(\sigma_{2}-\sigma_{3}\right) /\left(\sigma_{1}-\sigma_{3}\right)\right)$, one with $\sigma_{1}$ in the same direction as in the previous loading, one with $\sigma_{1}$ perpendicular to that direction; two tests at $b=1$ with $\sigma_{1}$ parallel and perpendicular to the direction of previous loading; one test at $b=0.5$ with $\sigma_{1}$ in the direction of previous loading, $\Theta_{\sigma}$ represents the angle between the initial loading and the following stress path in the octahedral plane.

Strength development is much faster when $\sigma_{1}$ is applied in the same direction as for the initial compression $\left(\Theta_{\sigma}=0^{\circ}, 30^{\circ}, 60^{\circ}\right)$. The deviatoric strain isovalue lines express this change in initial stiffness with the orientation of major principal stress (Figure 30). In comparison with the ones obtained from isotropic samples, they present a translation along the axis of initial loading which suggests a kinematic hardening created by plastic deformations due to particle reorientation during the axisymmetric compression.

The influence of initial anisotropy is erased by subsequent large plastic deformations. This can be observed in the octahedral plane where the deviatoric strain isovalue curves becomes identical for isotropic and anisotropic samples. As a consequence, the maximum shear strength and therefore the failure criterion appear in this case to be independent of the initial anisotropy.

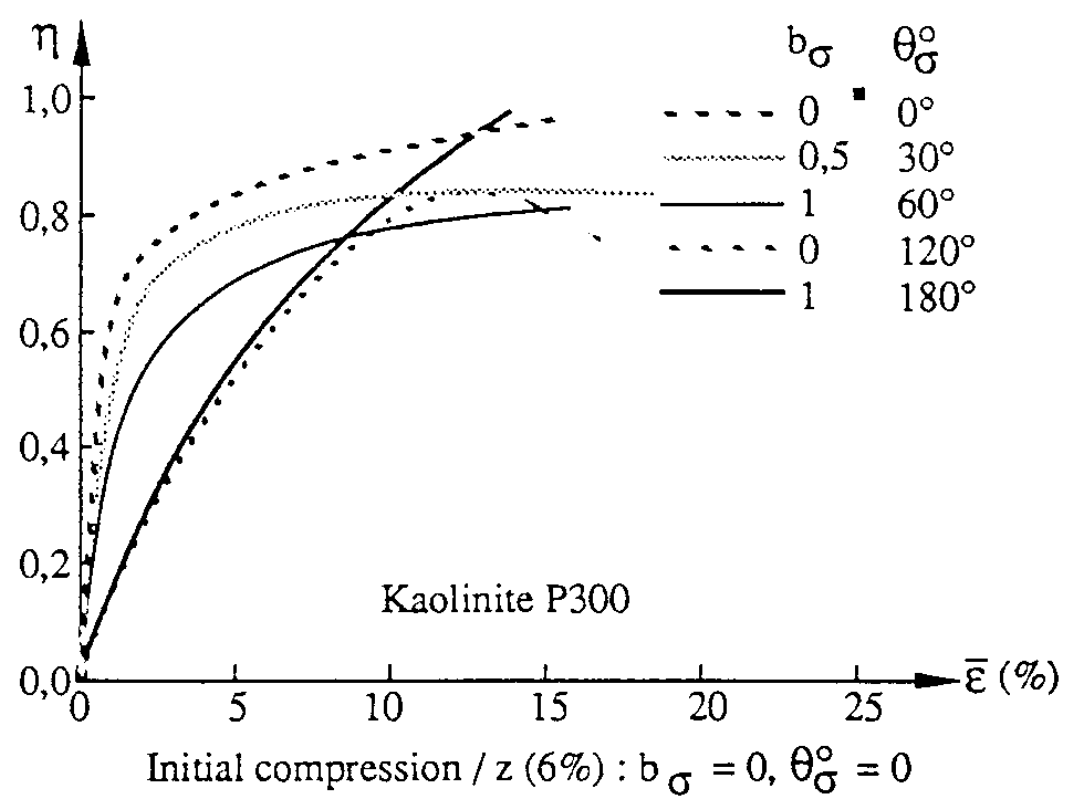

Figure 29. 3D tests on anisotropic kaolinite specimen. 

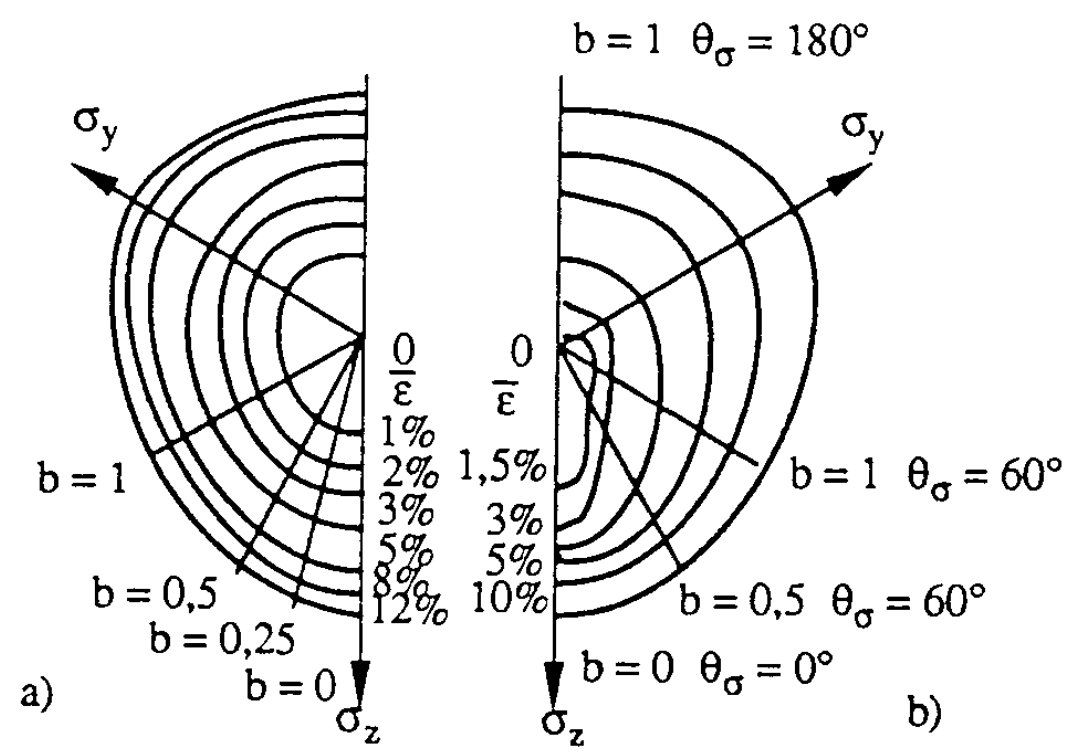

Kaolinite P300

Figure 30. Influence of initial anisotropy on the 3D behaviour of kaolinite. Isodeformation lines in the octahedral plane for proportional 3D loading.

\section{CONCLUSION}

In attempting to relate the mechanical behaviour to the structural characteristics of clay samples, we have used a variety of experimental techniques in order to describe these relationships at different scales ranging from the scale of layers, the nanometic level, to the scale of aggregates, the micrometic level. These techniques were based on quantitative and qualitative physical methods, such as scanning electron microscopy in an initially hydrated state. Particular care was taken to avoid as for as possible disturbing the micro-structure during observation.

\section{Micro-organization of clay particles}

Progressive ruptures of the clay particles took place during mechanical loading. The big aggregates (composed of several individual particles) were first affected and so they progressively split into smaller elements. The individual particles could also be affected; that is, rupturing occurred by delamination in a plane that was parallel to the layers. In the case of the bentonite micropores, inter-crystallite and/or discontinuities were found within a tactoid which created a zone of weakness that facilitated the delamination process. This continuous breaking during loading reduced the size of the clay elements which subsequently also reduced the size of the pores. Results from our mercury porosimetry confirmed these changes in the pore size.

Along with this important size change, we observed a structural re-organization during onedimensional and triaxial testing. This phenomenon was predominant in the case of one-dimensional loading, especially in the bentonite samples, because these particles were larger and more flexible than in the kaolinite samples. This led, for high consolidation stresses, to a very strong anisotropy in the clay structure. The use of rose diagrams from the photos obtained by the SEM 
allowed us to quantify the anisotropy by determining the different orientations of the particles in horizontal and vertical planes.

\section{Relationship between micro-organization and mechanical properties}

Mechanical properties of clays are much influenced by changes which occur in the microstructure. An increase in density leads to an increase of mechanical properties (stiffness and maximum strength) which can be considered proportional to the maximum consolidation stress as long as the breakage of the particles remains minimal. For high consolidation stresses, this is no longer the case and an influence of grain breakage can be observed on the evolution of the stress-strain relationship which shows an increase in ductility accompanied by a decrease in the maximum strength ratio (or in the friction angle).

The anisotropy of the arrangement of the particles created an anisotropy of their mechanical behaviour. Conventional triaxial tests on one-dimensionally consolidated samples show an important change in stiffness between 'vertical' samples (where loading occurs in the direction of consolidation) and 'horizontal' ones. The rigidity of the particle assembly is stronger when the load is applied in a direction perpendicular to the main direction of particle orientation, rather than in the same direction. The observed stiffness of 'horizontal' clay samples can easily be two times lower than that of the 'vertical' samples. For the former it can also be observed that $\varepsilon_{1}$ and $\varepsilon_{2}$ are different. Three-dimensional tests performed on anisotropic samples (submitted to a previous axisymetric loading) have generally shown that stiffness decreases significantly when the direction of the initial loading passes from the direction of the principal major stress to that of the intermediate stress and finally to the minor stress.

It therefore appears that mechanical loading has an impact at various levels on the structural organization of a clay and that the changes produced should be taken into account in order to understand better the mechanical behaviour of clay samples along stress and strain paths.

\section{APPENDIX NOTATION}

$\begin{array}{ll}\sigma_{1}, \sigma_{2}, \sigma_{3} & =\text { major, intermediate, minor principal stress } \\ \varepsilon_{1}, \varepsilon_{2}, \varepsilon_{3} & =\text { major, intermediate, minor principal strain } \\ C_{\mathrm{C}} & =\text { compressibility Index } \\ \mathrm{OCR} & =\text { overconsolidation ratio } \\ I_{\mathrm{f}} & =\text { particle shape index } \\ S_{\mathrm{a}} & =\text { particle mean surface } \\ D_{\mathrm{p}} & =\text { particle concentration } \\ I_{\max } & =\text { maximum anisotropy intensity } \\ I_{\mathrm{or}} & =\text { orientation index }\end{array}$

REFERENCES

1. Roscoe KH, Burland IB. On the generalised stress-strain behaviour of wet clay. Engineering Plasticity. Cambridge, 1968; 535-609. 
2. Schofield AN, Wroth CP. Critical State Soil Mechanics. McGraw-Hill: London, 1968.

3. Hicher PY. Comportement mécanique des argiles saturées sur divers chemins de sollicitations monotones et cyclique. Application à une modélisation élastoplastique et viscoplastique. Th. Doct. es Scies, Univ. Paris VI, 1985.

4. Biarez J, Hicher PY. Elementary Mechanics of Soil Behaviour. Ed Balkema, 1994; 208pp.

5. Diamond S. Microstructure and pore structure of impact-compacted clays. Clays and Clay Minerals 1971; 19:239-249.

6. Barden L, Sides G. Some disturbance in the investigation of clay structure. Geotechnique 1971; 12:211-222.

7. Smart P. A microstructural view of the mechanical properties of saturated clay. Geotechnique 1972; 22:368-371.

8. Collins K, McGown A. The form and function of microfabric features in a variety of natural soils. Geotechnique 1974; 24:233-254.

9. Pusch R. Mineral-water interactions and their influence on the physical behavior of highly compacted Na Bentonite. Canadian Geotechnical Journal 1982; 19:381-387.

10. Tessier D. Etude expérimentale de l'organisation des matériaux argileux. Hydratation, gonflement et structuration au cours de la dessication et de la réhumectation. Th. Doct. es Scies., Univ. Paris VII, 1984.

11. Tessier D. Behaviour and microstructure of clay minerals. In: Soil Colloids and their Associations in Aggregates. De Boodt MF et al. (eds), NATO Advances Series. Plenum Press: New York, 1991; 387-415.

12. Ben Rhaiem H, Pons CH, Tessier D. Factors affecting the microstructure of smectites. Role of cation and history of applied stresses. Special issue Proceedings of International Clay Conference, Denver, Clay and Clay Minerals, The clay Minerals Society, 1987; 292-297.

13. Pusch R. Microstructural changes in soft quick clay at failure. Canadian Geotechnical Journal 1997; 7:1-7.

14. Martin RT, Ladd CC. Fabric of consolidated kaolinite. Clays and Clay Minerals 1978; 23:17-25.

15. Delage P, Lefebvre G. Study of the structure of a sensitive Champlain clay and its evolution during consolidation. Canadian Geotechnical Journal 1984; 21:21-35.

16. Diamond S. Pore size distribution in clays. Clays and Clay Minerals 1970, 18:7-23.

17. Griffiths FJ, Joshi RC. Change in pore size distribution due to consolidation of clays. Geotechnique 1989; 39(1): 159-167.

18. Tessier D, Berrier J. Utilisation du microscope électronique à balayage dans l'étude des sols. Observation de sols humides à différents pF. Science du Sol, 1979; 1:67-82.

19. Delage P, Tessier D, Mareil-Audiguier M. Use of cryoscan apparatus for observation of freeze-fractured planes of a sensitive Québec clay. Canadian Geotechnical Journal 1982; 19(1):111-114.

20. Tessier D. Electron microscopy studies of clay microstructure. Clay Swelling and Expansive Soils. Baveye $\mathrm{Ph}, \mathrm{Mac}$ Bryte M. (eds), NATO Advances Series. Plenum Press: New York, 1995, in press.

21. Gillott JE. Importance of Specimen Preparation in Microscopy. American Society for Testing and Materials, STP 599, 1976; 289-307.

22. Hicher PY, Wahyudi H, Tessier D. Microstructural analysis of strain localisation in clay. Computers and Geotechnics 1994; 16:205-222.

23. Naskos NA. Quelques aspects du comportement mécanique de l'argile saturée, consolidée sous fortes pressions. Th. Doct. Ecole Centrale Paris, 1985.

24. Hicher PY, Trueba V. Induced anisotropy in normally consolidated clay, 3rd International Conference on Constitutive Laws for Eng. Materials. Tucson, U.S.A., 1991.

25. Bruand A, Tessier D. Etude de l'organisation d'un matériau argileux en microscopie: modifications intervenant lors de la déshydration. Micromorphologie des Sols/Soil Micromorphology, Fedoroff, Bresson et Courty Eds, AFES, 1987; $31-35$.

26. Kim JM, Peacor DR, Tessier D, Elsass F. A technique for maintaining texture and permanent expansion of smectite interlayer spacings for TEM observations. Clay and Clay Minerals, 1995.

27. Lapierre C, Leroueil S, Locat J. Mercury intrusion and permeability of Louiseville clay. Canadian Geotechnical Journal 1990; 27:761-773.

28. Pons, CH. Tessier D, Ben Rahiem, Tchoubar D. A comparison between X-ray studies and electron microscopy. Observation of smectite fabric. Developments in Sedimentology 1982; 35:177-183.

29. Wahyudi $\mathrm{H}$. Etude des propriétés mécaniques des matériaux argileux en relation avec leur organisation à différentes échelles. Th, Doct. Ecole Centrale Paris, 1991. 